\title{
Heparan Sulfate Heterogeneity in Skeletal Muscle Basal Lamina: Demonstration by Phage Display-Derived Antibodies
}

\author{
Guido J. Jenniskens, Arie Oosterhof, Ricardo Brandwijk, Jacques H. Veerkamp, and Toin H. van Kuppevelt \\ Department of Biochemistry, Faculty of Medical Sciences, University of Nijmegen, 6500 HB Nijmegen, The Netherlands
}

The basal lamina $(\mathrm{BL})$ enveloping skeletal muscle fibers contains different glycoproteins, including proteoglycans. To obtain more information on the glycosaminoglycan moiety of proteoglycans, we have selected a panel of anti-heparan sulfate (HS) antibodies from a semisynthetic antibody phage display library by panning against glycosaminoglycan preparations derived from skeletal muscle. Epitope recognition by the antibodies is strongly dependent on $\mathrm{O}$ - and $\mathrm{N}$-sulfation of the heparan sulfate. Immunostaining with these antibodies showed a distinct distribution of heparan sulfate epitopes in muscle basal lamina of various species. Clear differences in staining intensity were observed between neural, synaptic, and extrasynaptic basal

The basal lamina (BL) enveloping skeletal muscle fibers plays various roles in muscle development and regeneration (Sanes, 1986; Wright et al., 1991). Several BL molecules have been identified as specifically synaptic, extrasynaptic, or common (Sanes, 1982; Hall and Sanes, 1993). On the protein level, these include isoforms of laminin, collagen, and entactin (Sanes et al., 1990; Chiu and Ko, 1994; Patton et al., 1997). Lectin staining (Sanes and Cheney, 1982; Iglesias et al., 1992) and a recent report on synapse-specific carbohydrates (Martin et al., 1999) indicate a spatial heterogeneity for carbohydrates as well.

Heparan sulfate proteoglycans (HSPGs), consisting of a core protein and a carbohydrate moiety [heparan sulfate (HS)], are main components of muscle BLs. So far, three BL HSPGs have been identified: perlecan, agrin, and type XVIII collagen (Noonan et al., 1991; Tsen et al., 1995; Halfter et al., 1998). HSPGs are implicated in developmental processes underlying myogenesis and synaptogenesis (Anderson and Fambrough, 1983; Anderson et al., 1984; Bayne et al., 1984; Dmytrenko et al., 1990). Perlecan may effect neuromuscular junction (NMJ) formation by binding growth factors (Peng et al., 1998). Agrin, a major HSPG of the synaptic BL (sBL), orchestrates acetylcholine receptor (AChR) clustering (Campanelli et al., 1994; Ruegg and Bixby, 1998). Heparin and HS are involved in AChR clustering induced by nerve (Hirano and Kidokoro, 1989) and agrin (Wallace, 1990). In muscle cell lines defective in glycosaminoglycan

\footnotetext{
Received Aug. 18, 1999; revised March 23, 2000; accepted March 24, 2000.

This work was supported by Grant 902-27-184 from the Netherlands Organization for Scientific Research (NWO). We thank Dr. G. Winter for providing the phage display "scFv library \#1," Dr. Z. Hall for providing the glycosylation-deficient $\mathrm{S}_{27}$ cell line, Dr. J. Esko for providing glycosylation-deficient $\mathrm{CHO}$ cell lines, E. Versteeg for helpful discussions, Dr. T. Lamers for interpretation of the rat embryo experiments, T. Hafmans for help with graphics, and Dr. H. Dodemont for critical reading of this manuscript.

Correspondence should be addressed to Toin H. van Kuppevelt, Department of Biochemistry, 160, Faculty of Medical Sciences, University of Nijmegen, P.O. Box 9101, 6500 HB Nijmegen, The Netherlands. E-mail: a.vankuppevelt@bioch.kun.nl. Copyright (C) 2000 Society for Neuroscience $0270-6474 / 00 / 204099-13 \$ 15.00 / 0$
}

laminae. Moreover, temporal and regional changes in abundancy of heparan sulfate epitopes were observed during muscle development both in vitro and in vivo. Taken together, these data suggest a role for specific heparan sulfate domains/species in myogenesis and synaptogenesis. Detailed analysis of the functions of heparan sulfate epitopes in muscle morphogenesis has now become feasible with the isolation of antibodies specific for distinct heparan sulfate epitopes.

Key words: heparan sulfate proteoglycan; glycosaminoglycan; basal lamina; neuromuscular junction; myogenesis; synaptogenesis

(GAG) synthesis, a causal relationship between GAGs and AChR clustering is demonstrated (Ferns et al., 1993; Gordon et al., 1993; Mook-Jung and Gordon, 1996). HS binding may also mediate the synapse-specific anchoring of BL-resident proteins such as acetylcholine esterase and possibly certain laminin isoforms (Brandan et al., 1985; San Antonio et al., 1993; Patton et al., 1997).

Another major characteristic of HS is the binding of growth factors such as neuregulin (Fischbach and Rosen, 1997), midkine (Zhou et al., 1997), heparin-binding growth-associated molecule (Peng et al., 1995; Szabat and Rauvala, 1996), heparin-binding epidermal growth factor-like growth factor (Chen et al., 1995), and basic fibroblast growth factor. The latter protein is involved in postsynaptic differentiation (Peng et al., 1991) and maintenance of the proliferative state of satellite cells (Rapraeger et al., 1991; Olwin and Rapraeger, 1992; Olwin et al., 1994; Crisona et al., 1998). Considering the diversity of proteins that bind HS, HS molecules may contain unique domains (epitopes) that are specific for these interactions.

Studies of HSPGs have mainly been focused on the protein core. The structure and the role of the HS moiety are difficult to investigate because of a lack of appropriate tools. Only a few antibodies that recognize HS epitopes have been described (David et al., 1992; van den Born et al., 1992). Recently, we adapted phage display technology to obtain epitope-specific antibodies against HS (van Kuppevelt et al., 1998). Here we report on the isolation, characterization, and application of antibodies selected against HS-containing GAG preparations from skeletal muscle. We provide evidence for the existence of several specific, differentially distributed HS epitopes in (synaptic and extrasynaptic) muscle and nerve BLs. Moreover, we found a shift in abundancy of these epitopes in BLs of developing muscle both in vitro and in vivo. These data suggest an involvement of specific HS epitopes in myogenesis and synaptogenesis. 


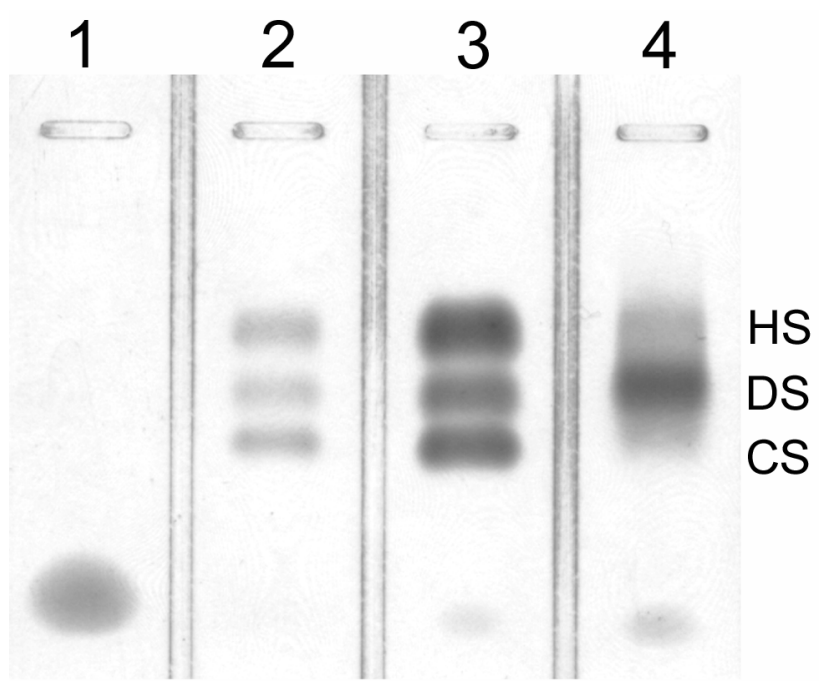

Figure 1. Silver-stained $1 \%$ agarose gel of a muscle glycosaminoglycan preparation. Lane 1, Sample buffer (control); lane 2, 5 ng GAG standard; lane 3, 20 ng GAG standard; lane 4, typical glycosaminoglycan preparation of mouse skeletal muscle. Dermatan sulfate $(D S)$ is present at approximately fourfold higher concentration compared with chondroitin sulfate $(C S)$ and heparan sulfate $(H S)$.

\section{MATERIALS AND METHODS}

Materials. Synthetic single-chain variable fragment (scFv) library \#1 (Nissim et al., 1994) was generously provided by Dr. G. Winter (Cambridge University, Cambridge, United Kingdom). Human skeletal muscle samples were generously provided by Prof. Dr. D. Ruiter (Department of Pathology, University of Nijmegen, Nijmegen, The Netherlands). Torpedo marmarota electric organ was generously provided by Dr. M. H. De Baets (Department of Immunology, University of Maastricht, Maastricht, The Netherlands). Mice (C3H, male, $70 \mathrm{~d})$, rats (Wistar, male, six weeks), and rat embryos (Wistar, 10, 13, 16, and $19 \mathrm{~d}$ after conception) were obtained from the University of Nijmegen Central Animal Laboratory. $\mathrm{C} 3 \mathrm{H}$ mouse-derived skeletal muscle $\left(\mathrm{C}_{2} \mathrm{C}_{12}\right)$ cell line was purchased from American Type Culture Collection (Rockville, $\mathrm{MD})$. Glycosaminoglycan-deficient myoblast $\left(\mathrm{S}_{27}\right)$ cell line was a generous gift of Dr. Z. Hall (Department of Physiology, University of California, San Francisco, CA); mutant Chinese hamster ovary (CHO) cell lines were kindly provided by Dr. J. Esko (Department of Biochemistry, University of Alabama, Birmingham, AL).

For phage display, two Escherichia coli strains were used: suppressor strain TG1 [K12, sup E, hsd $\Delta 5$, thi $\Delta($ lac-proAB $), \mathrm{F}^{\prime}\left(\right.$ tra $\mathrm{D} 36$, proAB ${ }^{+}$, lac $\mathrm{I}^{\mathrm{q}}$, lac $\left.\left.\mathrm{Z} \Delta \mathrm{M} 15\right)\right]$ and nonsuppressor strain $\mathrm{HB} 2151$ [K12, ara, thi $\Delta$ (lac-pro), $\mathrm{F}^{\prime}\left(\right.$ proAB $^{+}$, lac $\left.\left.^{\mathrm{q}}, \mathrm{Z} \Delta \mathrm{M} 15\right)\right]$. Helper phage VCS-M13 was from Stratagene (La Jolla, CA).

All chemicals used were purchased from Merck (Darmstadt, Germany), unless stated otherwise. Bacterial media (2xTY and LB) and cell culture media were from Life Technologies (Paisley, Scotland). Chondroitinase ABC (from Proteus vulgaris, EC 4.2.2.4), chemically modified heparin kit, anti-chondroitin sulfate (CS) "stub" antibody (2B6), and anti-heparan sulfate stub antibody (3G10) were from Seikagaku Kogyo Co. (Tokyo, Japan). Heparinase III (from Flavobacterium heparinum, EC 4.2.2.8), heparan sulfate from bovine kidney and porcine intestinal mucosa, heparin from porcine intestinal mucosa, chondroitin 4-sulfate and chondroitin 6-sulfate from bovine trachea, dermatan sulfate (DS) from porcine intestinal mucosa, keratan sulfate from bovine cornea, hyaluronic acid from human umbilical cord, DNA from calf thymus, phenylmethylsulfonyl fluoride (PMSF), $N$-ethylmaleimide, aprotinin, sodium azide, pepstatin $\mathrm{A}$, and bovine serum albumin (fraction $\mathrm{V}$ ) were from Sigma (St. Louis, MO). Microlon 96-well microtiter plates and immunotubes were from Greiner (Frickenhausen, Germany). Anti-c-Myc tag mouse monoclonal IgG (clone 9E10) was from Boehringer Mannheim (Mannheim, Germany), Anti-c-Myc tag rabbit polyclonal IgG (A-14) was from Santa Cruz Biotechnology (Santa Cruz, CA). Alkaline phosphataseconjugated rabbit anti-mouse IgG was from Dakopatts (Glostrup, Denmark). Alexa 488-conjugated goat anti-rabbit IgG and tetramethylrhodamine isothiocyanate (TRITC)-conjugated $\alpha$-bungarotoxin were from
Table 1. CDR3 sequences and germline $V_{H}$ gene segments of anti-HS scFv antibodies

\begin{tabular}{lllc} 
Clone & CDR3 sequence & $\mathrm{V}_{\mathrm{H}}$ family & DP segment \\
\hline AO4B05 & LKQQGIS & 3 & 53 \\
AO4B08 & SLRMNGWRAHQ & 3 & 47 \\
AO4F12 & AMTQKKPRKLSL & 1 & 7 \\
RB4CB9 & HAPLRNTRTNT & 3 & 38 \\
RB4CD12 & GMRPRL & 3 & 38 \\
RB4EA12 & RRYALDY & 3 & 32 \\
RB4EG12 & SGRKYFRARDMN & 1 & 4
\end{tabular}

Antibodies with the prefix AO were obtained after panning against GAGs from mouse skeletal muscle, whereas antibodies with the prefix RB were selected by panning against GAGs isolated from human skeletal muscle. CDR3 sequences are shown in single-letter amino acid code. $\mathrm{V}_{\mathrm{H}}$ families and DP segments were deduced from the Sanger Centre Germline Quiry (http://www.sanger.ac.uk/DataSearch/ gq_search.shtml) by applying the full-length $\mathrm{V}_{\mathrm{H}}$ sequences of the anti-HS scFv antibody clones (nomenclature according to Tomlinson et al., 1992).

Molecular Probes (Eugene, OR). Mowiol (4-88) was from Calbiochem (La Jolla, CA). PCR chemicals and Taq polymerase (DNA polymerase from Thermus aquaticus) were from Promega (Madison, WI), PCR primers were from Biolegio (Malden, The Netherlands), and restriction enzyme Bst NI was from New England Biolabs (Beverly, MA). ABI Prism Big Dye Terminator Cycle Sequencing Ready Reaction Kit was from PE Applied Biosystems (Norwalk, CT).

All experiments were performed at ambient temperature $\left(21^{\circ} \mathrm{C}\right)$, unless stated otherwise.

Isolation of glycosaminoglycans from skeletal muscle. Mouse and human skeletal muscle specimens were homogenized, defatted in $20 \mathrm{vol}$ of acetone at $-20^{\circ} \mathrm{C}$ for $16 \mathrm{hr}$, and dried in a desiccator. Per gram of muscle tissue, $4 \mathrm{ml} 50 \mathrm{~mm}$ sodium phosphate buffer, $\mathrm{pH} 6.5$, containing $2 \mathrm{~mm}$ EDTA, 2 mm cysteine, and $10 \mathrm{U}$ papain were added. Papain digestion was performed for $16 \mathrm{hr}$ at $65^{\circ} \mathrm{C}$, and the remaining debris was pelleted. Residual protein fragments were removed from the glycosaminoglycans by mild alkaline borohydride digestion in $0.5 \mathrm{M} \mathrm{NaOH} / 0.05 \mathrm{M} \mathrm{NaBH}_{4}$ at $4^{\circ} \mathrm{C}$. After overnight digestion, the mixture was neutralized by addition of $6 \mathrm{M} \mathrm{HCl}$. Residual protein fragments were precipitated by addition of $100 \%(\mathrm{w} / \mathrm{v})$ trichloroacetic acid to a final concentration of $6 \%$ and precipitation at $0^{\circ} \mathrm{C}$ for $1 \mathrm{hr}$. Precipitated proteins were removed by centrifugation $\left(10,000 \times g\right.$ for $20 \mathrm{~min}$ at $\left.4^{\circ} \mathrm{C}\right)$, and glycosaminoglycans were isolated by addition of $5 \mathrm{vol}$ of $100 \%$ ethanol to the supernatant and overnight precipitation at $-20^{\circ} \mathrm{C}$. After centrifugation $(10,000 \times g$ for 30 min at $4^{\circ} \mathrm{C}$ ), the pelleted glycosaminoglycans were washed with $70 \%$ ethanol, dried, and dissolved in $10 \mathrm{~mm}$ Tris- $\mathrm{HCl}, \mathrm{pH}$ 6.8. This crude glycosaminoglycan preparation was further deprived of protein contamination by DEAE Sepharose column chromatography, eluting glycosaminoglycans at $0.5 \mathrm{M}$ and $1.0 \mathrm{M} \mathrm{NaCl}$ in $10 \mathrm{~mm}$ Tris- $\mathrm{HCl}, \mathrm{pH}$ 6.8. GAGcontaining eluates were pooled, and after ethanol precipitation the residual salt was removed by a $70 \%$ (v/v) ethanol wash. The resulting glycosaminoglycan preparations were dissolved in MilliQ water and stored at $4^{\circ} \mathrm{C}$.

Phage display. Phage display was essentially performed as described (Van Kuppevelt et al., 1998). Synthetic scFv library \#1 was subjected to four rounds of panning against mouse or human skeletal muscle glycosaminoglycan preparations. The library contains approximately $10^{8}$ different $\mathrm{scFv}$ antibody clones, composed of 50 different heavy $\left(\mathrm{V}_{\mathrm{H}}\right)$ chain $\mathrm{V}$ segments with synthetic (randomly synthesized) complementaritydetermining region 3 (CDR3) fragments and one light $\left(\mathrm{V}_{\mathrm{L}}\right)$ segment. This library was in vitro-synthesized from $\mathrm{V}$ gene segments, derived from human lymphocytes, using PCR (Tomlinson et al., 1992; Nissim et al., 1994). After the last round of selection, single colonies were picked, and the antibodies expressed by these clones were evaluated for reactivity by ELISA. Clones displaying reactive antibodies were further analyzed by colony-PCR amplification of the antibody coding region and restriction

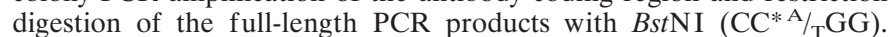
Unique clones were grown at a larger scale, and individual plasmid DNAs were sequenced using PelB-seq (5'-CCGCTGGATTGTTATTACTC-3') as a primer (located within the PelB leader sequence).

Large scale preparation of antibodies. To produce large quantities of scFv antibodies, plasmid DNA from selected clones was used to transform nonsuppressor E. coli strain HB2151. Five hundred milliliters of 
Table 2. Evaluation of anti-HS antibody specificity by ELISA

\begin{tabular}{|c|c|c|c|c|c|c|c|}
\hline GAG preparation & AO4B05 & AO4B08 & AO4F12 & RB4CB9 & RB4CD12 & RB4EA12 & RB4EG12 \\
\hline K5 capsular polysaccharide $(E . \text { coli })^{a}$ & - & - & - & - & - & - & - \\
\hline HS (bovine kidney) & ++ & +++ & + & $+/-$ & ++ & $+/-$ & $+/-$ \\
\hline HS (porcine intestinal mucosa) & ++ & ++ & $+/-$ & + & + & + & $+/-$ \\
\hline HS (human lung, $0.5 \mathrm{M} \mathrm{NaCl}$ fraction) ${ }^{b}$ & + & $+1-$ & - & - & - & + & $+1-$ \\
\hline HS (human lung, $1.0 \mathrm{M} \mathrm{NaCl}$ fraction) ${ }^{b}$ & ++ & +++ & ++ & + & ++ & ++ & ++ \\
\hline Heparin (porcine intestinal mucosa) & ++ & +++ & +++ & + & +++ & ++ & +++ \\
\hline Heparin, desulfated and $N$-acetylated ${ }^{c}$ & - & - & - & - & - & - & - \\
\hline Heparin, desulfated and $N$-sulfated ${ }^{c}$ & - & - & - & - & - & - & - \\
\hline Heparin, $N$-desulfated and $N$-acetylated ${ }^{c}$ & - & - & $+/-$ & - & - & - & - \\
\hline
\end{tabular}

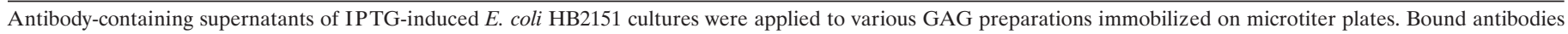

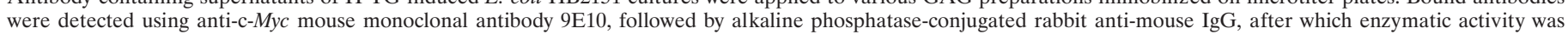
measured using $p$-nitrophenyl phosphate as a substrate. Substrate affinity: +++ , very strong; ++ , strong; + , moderate; $+/-$, weak; - , absent $(n=5)$.

${ }^{a}$ Similar to the HS precursor polysaccharide.

${ }^{b} \mathrm{HS}$ fraction eluting from anion exchange column at the $\mathrm{NaCl}$ concentration indicated.

${ }^{c}$ Inhibition-ELISA.

prewarmed 2xTY medium containing $0.1 \%(\mathrm{w} / \mathrm{v})$ glucose and $100 \mu \mathrm{g} / \mathrm{ml}$ ampicillin were inoculated with an overnight culture of transformed $\mathrm{HB} 2151$ and grown with vigorous shaking at $37^{\circ} \mathrm{C}$ until an $\mathrm{OD}_{600}$ of 0.3 was reached. Induction was effectuated by addition of isopropyl- $\beta$-Dthiogalactopyranoside (IPTG) to a final concentration of $1 \mathrm{mM}$. After 3 $\mathrm{hr}$ incubation at $30^{\circ} \mathrm{C}$ the culture was cooled on ice for $20 \mathrm{~min}$, and cells were pelleted $\left(3000 \times g\right.$ for $10 \mathrm{~min}$ at $\left.4^{\circ} \mathrm{C}\right)$. One-tenth volume of $10 \times$ protease inhibitor mix [0.1 M EDTA, $250 \mathrm{~mm}$ iodoacetamine, $1 \mathrm{M}$ $n$-ethylmaleimide, $1 \%(\mathrm{w} / \mathrm{v}) \mathrm{NaN}_{3}, 1.5 \mathrm{mTIU} / \mathrm{ml}$ aprotinin, $0.1 \%(\mathrm{w} / \mathrm{v})$ pepstatin A, $1 \mathrm{~mm}$ PMSF] was added to the supernatant, which was subsequently divided into aliquots and stored at $4^{\circ} \mathrm{C}$. The cells were resuspended by vigorous vortexing in $5 \mathrm{ml}$ ice-cold $200 \mathrm{~mm}$ sodium borate buffer, $\mathrm{pH}$ 8.0, containing $160 \mathrm{~mm} \mathrm{NaCl}, 1 \mathrm{~mm}$ EDTA, and protease inhibitors. After centrifugation $\left(5000 \times g\right.$ for $30 \mathrm{~min}$ at $\left.4^{\circ} \mathrm{C}\right)$, the supernatant (the periplasmic fraction containing the $\mathrm{scFv}$ antibodies) was filtered through a $0.45 \mu \mathrm{m}$ filter, dialyzed overnight at $4^{\circ} \mathrm{C}$ against PBS, divided into aliquots, and stored at $-20^{\circ} \mathrm{C}$.

Evaluation of antibody specificity by ELISA. Unless stated otherwise, supernatants of IPTG-induced HB2151 cultures were used for ELISA. Affinity of the antibodies to various molecules was evaluated by ELISA in two ways: scFv antibodies were applied to wells of Microlon microtiter plates, coated with the molecule concerned $(10 \mu \mathrm{g} / \mathrm{ml}$ coating solution), and allowed to bind for $90 \mathrm{~min}$. Alternatively, $\mathrm{scFv}$ antibodies were preincubated overnight with the test molecule $(10 \mu \mathrm{g} / \mathrm{ml})$ in $\mathrm{PBS} / 0.1 \%$ (w/v) Marvel, followed by transfer to and 90 min incubation in wells previously coated with heparin. Test molecules included glycosaminoglycan preparations from mouse and human skeletal muscle, HS preparations from bovine kidney and human lung, prepared as described above, commercially available heparan sulfate from bovine kidney and from porcine intestinal mucosa, heparin, chemically and enzymatically modified heparin, chondroitin 4-sulfate, chondroitin 6-sulfate, dermatan sulfate, keratan sulfate, hyaluronic acid, DNA, Marvel, and bovine serum albumin (fraction V). Bound scFv antibodies were detected using anti-cMyc mouse monoclonal antibody 9E10, followed by alkaline phosphatase-conjugated rabbit anti-mouse $\operatorname{IgG}(60 \mathrm{~min}$ each). Plates were washed three times with PBS containing $0.1 \%$ (v/v) Tween-20 (PBST) after each incubation. Enzyme activity was detected using 1 $\mathrm{mg} / \mathrm{ml} p$-nitrophenyl phosphate in $1 \mathrm{M}$ diethanolamine $/ 0.5 \mathrm{~mm} \mathrm{MgCl}_{2}$, $\mathrm{pH}$ 9.8, and absorbance was read at $405 \mathrm{~nm}$.

Immunohistochemistry. Periplasmic fractions of IPTG-induced HB2151 cultures were used for immunohistochemistry, unless stated otherwise. Location of the epitopes recognized by the antibodies in several tissues was assessed both on cryosections of tissue specimens and on monolayers of cultured cell lines. Tissues included human skeletal muscle and diaphragm, rat and $\mathrm{C} 3 \mathrm{H}$ mouse skeletal muscle, rat denervated skeletal muscle, rat embryos, and T. marmarota electric organ. Tissue specimens were snap-frozen in liquid nitrogen-cooled isopentane and stored at $-80^{\circ} \mathrm{C}$. Wild-type and glycosylation-deficient $\mathrm{CHO}$ cell lines were studied at confluency, whereas myoblast $\left(\mathrm{C}_{2} \mathrm{C}_{12}\right.$ and $\left.\mathrm{S}_{27}\right)$ cell lines were analyzed at various stages of differentiation. Cells were grown as previously described (Portiér et al., 1999), differentiated in Ultroser brain extract medium, washed three times with PBS, dried overnight, and stored at $-80^{\circ} \mathrm{C}$. Cryosections $(3$ or $5 \mu \mathrm{m}$ ) or tissue cultures were rehydrated for $10 \mathrm{~min}$ in PBS, blocked with PBS containing $0.1 \%(\mathrm{w} / \mathrm{v})$ BSA for $20 \mathrm{~min}$, and incubated with scFv antibodies for $90 \mathrm{~min}$. Bound antibodies were detected using anti-c-Myc rabbit polyclonal antibody A-14 and Alexa 488-conjugated goat anti-rabbit IgG (60 min each). For visualization of AChR clusters, TRITC-conjugated $\alpha$-bungarotoxin was included in the final incubation. Cryosections or tissue cultures were washed three times with PBS after each incubation. Finally, the cryosections or tissue cultures were fixed in $100 \%$ methanol, dried, and embedded in Mowiol [10\% (w/v) in $0.1 \mathrm{~m}$ Tris-HCl, $\mathrm{pH} 8.5 / 25 \%$ (v/v) glycerol/ $\left.2.5 \%(\mathrm{w} / \mathrm{v}) \mathrm{NaN}_{3}\right]$. As a control, primary, secondary, or conjugated antibodies were omitted.

Evaluation of antibody specificity by immunohistochemistry. To assess the heparan sulfate specificity of the $\mathrm{scFv}$ antibodies, cryosections or tissue cultures were preincubated with heparinase III to digest heparan sulfate $\left[0.02 \mathrm{U} / \mathrm{ml}\right.$ in $\left.50 \mathrm{~mm} \mathrm{NaAc} / 50 \mathrm{~mm} \mathrm{Ca}(\mathrm{Ac})_{2}, \mathrm{pH} 7.0\right]$ overnight at $37^{\circ} \mathrm{C}$, or with chondroitinase $\mathrm{ABC}$, which digests chondroitin and dermatan sulfate $(1 \mathrm{U} / \mathrm{ml}$ in $25 \mathrm{~mm}$ Tris- $\mathrm{HCl}, \mathrm{pH} 8.0)$ for $30 \mathrm{~min}$ at $37^{\circ} \mathrm{C}$. As a control, cryosections or tissue cultures were incubated in the reaction buffer without enzyme. After washing three times with PBS and blocking with $\mathrm{PBS} / 0.1 \%(\mathrm{w} / \mathrm{v}) \mathrm{BSA}$, cryosections and tissue cultures were incubated with antibodies and processed for immunofluorescence as described above. The efficiency of chondroitinase ABC treatment was evaluated by incubation of cryosections with an antibody (2B6) against chondroitin sulfate "stubs," generated by chondroitinase. Heparan sulfate stubs were visualized using anti- $\Delta$-heparan sulfate antibody (3G10).

Denervation of rat skeletal muscle. The musculus gastrocnemius and the musculus soleus of the left legs of young adult rats were denervated by cutting the efferent motor nerves innervating these muscles. The ends of these nerves were fastened to the musculus biceps femoris to prevent reinnervation (Degens et al., 1992). After $11 \mathrm{~d}$, rats were killed, and the calves of both the left (denervated) and right (control) legs were isolated and processed as described in immunohistochemistry.

\section{RESULTS}

\section{Selection of antibodies against skeletal muscle GAGs}

To select scFv antibodies against skeletal muscle GAG epitopes, GAGs were isolated from human and $\mathrm{C} 3 \mathrm{H}$ mouse skeletal muscle. Typically, $10 \mu \mathrm{g}$ GAG could be purified from $1 \mathrm{gm}$ muscle tissue (wet weight). All GAG preparations contained approximately equal amounts of CS and HS and were approximately fourfold richer in DS (Fig. 1).

Four rounds of panning were performed against mouse skeletal muscle-derived GAG preparations, resulting in antibodies that bear the prefix AO. Antibodies with the prefix RB were obtained after panning against human skeletal muscle-derived GAGs. This approach yielded a set of unique anti-HS antibodies, based on the 
amino acid sequence of their heavy chain CDR3, a major determinant in antigen specificity (Table 1).

\section{Characterization of antibodies}

All antibodies showed a high reactivity in ELISA for the GAG preparation against which they were selected, whereas the reactivity for various GAG species derived from other tissues varied significantly. Despite the fact that the antibodies were selected against a GAG mixture that consisted predominantly of DS, antibodies showed affinity only for HS and heparin. No reactivity was observed with chondroitin 4-sulfate, chondroitin 6-sulfate, dermatan sulfate, keratan sulfate, hyaluronic acid, DNA, Marvel (blocking agent), and Microlon (data not shown). Antibodies reacted to various extents with a highly sulfated HS fraction (eluting at $1.0 \mathrm{M} \mathrm{NaCl}$ in ion exchange chromatography) and with a low-sulfated fraction (eluting at $0.5 \mathrm{M} \mathrm{NaCl}$ ) of human lung (Table 2). All antibodies showed a major cross-reactivity with heparin, which is highly sulfated. Antibodies AO4B05, AO4B08, and (to a somewhat lesser extent) RB4CD12 showed a high reactivity for $\mathrm{HS}$ from bovine kidney and porcine intestinal mucosa, whereas all other antibodies interacted only moderately or weakly. K5 capsular polysaccharide from E. coli, which is similar to the HS precursor, was not bound by any of the antibodies.

To investigate which chemical groups are recognized by the different antibodies, we determined the reactivity of the antibodies toward modified heparin preparations (Table 2). Completely desulfated and $N$-acetylated heparin as well as completely desulfated and $N$-sulfated heparin were not recognized by any of the antibodies. Heparin that was $N$-desulfated and $N$-acetylated also was not recognized by the antibodies, except for AO4F12, which showed a weak binding.

To ascertain the HS specificity of the antibodies, immunofluorescence studies were performed on cryosections of skeletal muscle tissue that were treated with heparinase III before incubation. Heparinase treatment of cryosections resulted in a total loss of staining for all antibodies (Fig. 2), whereas treatment with chondroitinase ABC did not (data not shown). Staining of heparinase-treated cryosections with anti-HS stub antibody $3 \mathrm{G} 10$ (which reveals all HS that is present) showed HS to be equally distributed in synaptic and extrasynaptic BL (Fig. 2c).

\section{Cell lines that are defective in GAG synthesis are not surface-stained by anti-HS antibodies}

To further establish the anti-HS nature of the scFv antibodies, we investigated cell lines that are defective in GAG synthesis. Developmental stages from half-confluent to $8 \mathrm{~d}$ of differentiation of the $S_{27}$ cell line (Gordon and Hall, 1989) and confluent cultures of different $\mathrm{CHO}$ cell lines [wild type, $\mathrm{N}$-acetylglucosaminyl- and glucuronosyltransferase-deficient; pgsD-677 (Lidholt et al., 1992), heparan sulfate uronic acid 2- $O$-sulfotransferase deficient; pgsF-17 (Dr. J. Esko, personal communication), and xylosyl transferase deficient; pgsA-745 (Esko et al., 1985)] were analyzed by immunofluorescence.

In contrast to wild-type myoblast cell line $\mathrm{C}_{2} \mathrm{C}_{12}$ (see below), the surface of $\mathrm{S}_{27}$ myoblasts was not immunoreactive for any of the antibodies, nor were places of cell-cell contact. On alignment and fusion, and at day 8 of differentiation, myotubes were not stained either, indicating that the BL of this mutant cell line does not contain any of the HS epitopes recognized by any of the antibodies (Table 3, Fig. 3). A noteworthy observation was the distinct staining of perinuclear and cytosolic granules by some antibodies (Table 3).
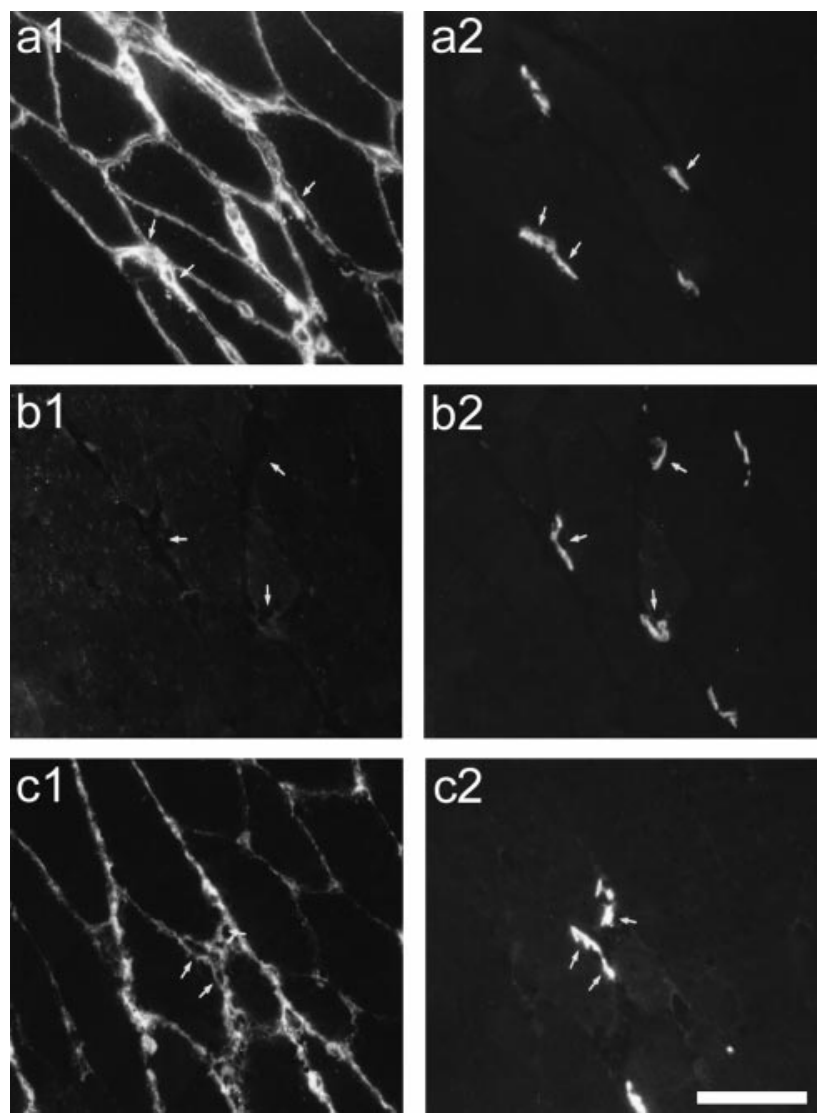

Figure 2. Staining of heparinase III-treated skeletal muscle cryosections with anti-HS scFv and anti-HS stub antibodies. Nontreated $(a)$ and heparinase III-treated $(b, c)$ cryosections of mouse skeletal muscle tissue were incubated with periplasmic fraction of anti-HS antibody AO4F12 $(a$, $b)$ or anti-heparan sulfate stub antibody $(3 \mathrm{G} 10)(c)$. Bound scFv antibodies were visualized by incubation with rabbit polyclonal anti-c-Myc $\operatorname{IgG}$ $(a 1, b 1)$, followed by Alexa 488-conjugated goat anti-rabbit or anti-mouse $\operatorname{IgG}(a$ and $b$, or $c$, respectively). AChR clusters present in the neuromuscular junction were visualized using TRITC-conjugated $\alpha$-bungarotoxin $(a 2-c 2)$. Although in untreated tissue the AO4F12 epitope is clearly present in the muscle BL (al), staining disappeared during heparinase treatment (b1), indicating the HS nature of the epitope. Staining of heparan sulfate stubs in heparinase-treated tissue showed HS to be present throughout the muscle BL $(c 1)$. Note the higher staining intensity of AO4F12 at NMJs (a1, a2, arrows), regardless of the overall quantity of HS in the NMJ (c1, c2, arrows). Scale bar, $50 \mu \mathrm{m}$.

Wild-type CHO cells showed a clear surface staining at sites of cell-cell contact when incubated with antibodies AO4B05, AO4B08, AO4F12, RB4CB9, and RB4CD12 (Table 3, Fig. 4a,b), whereas incubation with RB4EA12 and RB4EG12 did not (Table 3, Fig. 4c). None of the glycosylation-defective $\mathrm{CHO}$ mutant cell lines showed any surface staining (Fig. 4). As in the $S_{27}$ cell line, some antibodies showed a distinct staining of perinuclear and cytosolic granules (Table 3, Fig. 4).

\section{Anti-HS antibodies bind distinct HS epitopes in skeletal muscle basal lamina}

Incubation of cryosections of human, rat, and mouse skeletal muscle with each of the anti-HS antibodies yielded a clear staining of the muscle BL, which was similar in the species examined (Table 3, Fig. 5). Staining patterns of the antibodies on muscle BL were mutually distinct, ranging from a strong staining of the entire BL (AO4B05, AO4B08, AO4F12, RB4CB9, and 


\begin{tabular}{|c|c|c|c|c|c|c|c|}
\hline Tissue & AO4B05 & AO4B08 & $\mathrm{AO} 4 \mathrm{~F} 12$ & RB4CB9 & RB4CD12 & RB4EA12 & RB4EG12 \\
\hline \multicolumn{8}{|c|}{ Mature human, rat, and mouse skeletal muscle } \\
\hline Extrasynaptic basal lamina & ++ & ++ & ++ & ++ & ++ & $+/-$ & - \\
\hline Synaptic basal lamina & +++ & ++ & +++ & ++ & +++ & +++ & + \\
\hline Endoneurium and perineurium & ++ & + & +++ & + & +++ & +++ & + \\
\hline Capillary basal lamina & ++ & ++ & ++ & + & +++ & - & - \\
\hline Arterial basal lamina & ++ & + & ++ & ++ & ++ & - & - \\
\hline \multicolumn{8}{|l|}{ Electric organ (T. marmarota) } \\
\hline Electrocyte, noninnervated face & ++ & + & + & $+/-$ & ++ & $+/-$ & + \\
\hline Electrocyte, innervated face & ++ & + & + & ++ & ++ & $+1-$ & + \\
\hline Endoneurium & ++ & + & + & - & + & $+/-$ & + \\
\hline Perineurium & $+/-$ & + & ++ & ++ & + & - & $+/-$ \\
\hline \multicolumn{8}{|l|}{ Rat embryo skeletal muscle (19 d in utero) } \\
\hline Extrasynaptic basal lamina & ++ & ++ & ++ & + & +++ & - & $+/-$ \\
\hline Synaptic basal lamina & ++ & ++ & +++ & ++ & ++ & - & ++ \\
\hline Nerve basal lamina & ++ & ++ & +++ & ++ & +++ & $+/-$ & + \\
\hline Smooth muscle basal lamina (artery) & ++ & ++ & ++ & ++ & ++ & - & - \\
\hline \multicolumn{8}{|l|}{$\mathrm{C}_{2} \mathrm{C}_{12}$ skeletal muscle cell line } \\
\hline Cell surface (on contact places) & +++ & ++ & ++ & ++ & +++ & $-{ }^{d}$ & $-^{d}$ \\
\hline Basal lamina (during differentiation) & $++^{a}$ & $++^{a}$ & $++^{a}$ & + & $+++^{b}$ & $-^{d}$ & $-^{d}$ \\
\hline AChR clusters & $++^{a}$ & ++ & $+^{a}$ & ++ & +++ & - & - \\
\hline \multicolumn{8}{|c|}{$\mathrm{S}_{27}$ cell line (defective in proteoglycan synthesis) } \\
\hline Cell surface (on contact places) & - & $-^{d}$ & $-^{d}$ & $-^{d}$ & $-^{c}$ & $-^{d}$ & $-{ }^{d}$ \\
\hline Basal lamina (during differentiation) & - & $-{ }^{d}$ & $-{ }^{d}$ & $-{ }^{d}$ & $--^{c}$ & $-^{d}$ & - \\
\hline \multicolumn{8}{|l|}{ CHO cell line (wild type) } \\
\hline Cell surface & ++ & ++ & ++ & + & + & $-^{c}$ & $-^{d}$ \\
\hline \multicolumn{8}{|l|}{ CHO cell line (677 mutant) } \\
\hline Cell surface & - & - & $-^{d}$ & $-^{c}$ & $-^{c}$ & $-^{c}$ & $-^{d}$ \\
\hline \multicolumn{8}{|l|}{ CHO cell line (F17 mutant) } \\
\hline Cell surface & - & $-^{d}$ & $-{ }^{d}$ & $-^{c}$ & - & $-^{d}$ & $-^{d}$ \\
\hline \multicolumn{8}{|l|}{ CHO cell line (745 mutant) } \\
\hline Cell surface & - & - & - & $-^{c}$ & $-^{c}$ & $-^{d}$ & $-^{d}$ \\
\hline
\end{tabular}

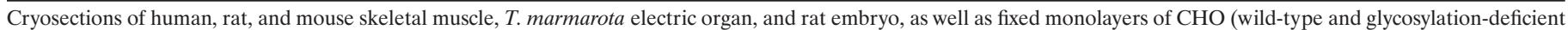

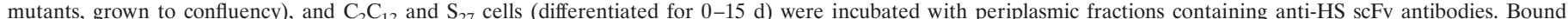

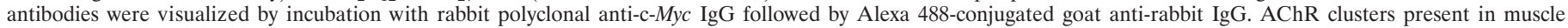

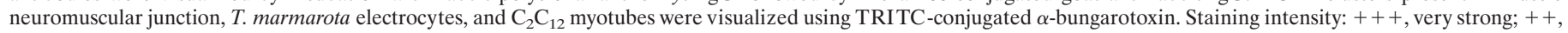
strong; + , moderate; $+/-$, weak; - , absent $[n=3$ (cryosections), $n=2$ (tissue cultures) .

${ }^{a}$ Staining intensity decreased with differentiation level.

${ }^{b}$ Staining intensity increased with differentiation level.

${ }^{c}$ Small granules within the cytosol: ++ .

${ }^{d}$ Small granules around the nucleus: ++ .

RB4CD12), to a staining concentrated in (RB4EA12), or almost exclusive for (RB4EG12) the sBL. Antibodies AO4B05, AO4F12, RB4CD12, RB4EA12, and RB4EG12 stained the sBL more intensely than the extrasynaptic BL. The BL of neural tissues showed very strong (AO4F12, RB4CD12, and RB4EA12), strong (AO4B05), or moderate (AO4B08, RB4CB9, and RB4EG12) staining. BLs of blood vessels showed strong to moderate (AO4B05, AO4B08, AO4F12, RB4CB9, and RB4CD12) or no (RB4EA12 and RB4EG12) staining. The latter two antibodies hardly stain muscle BL extrasynaptically and appear to be neuron- and synapse-specific. Most antibodies that stain blood vessels showed differences in staining intensity between arteries, large blood vessels, and capillaries.

The staining patterns of anti-HS antibodies provided convincing evidence for the existence and unique distribution of multiple HS epitopes within the skeletal muscle BL. To investigate the distribution of these HS epitopes with regard to the sBL, cryosections containing NMJs were incubated both with the antibodies and with TRITC-conjugated $\alpha$-bungarotoxin. $\alpha$-Bungarotoxin exclusively binds AChRs, thus allowing identification of NMJs. The AO4F12 epitope does not fully colocalize with AChR clusters, yet there is considerable overlap between the distribution of the AO4F12 epitope in the sBL and the presence of dense patches of AChR on the postsynaptic membrane (Fig. 5a1-a3). RB4CD12, on the other hand, showed an almost complete colocalization with AChR clusters (Fig. 5b1-b3). RB4EA12 showed a strong preference for neural and synaptic BL, thus completely colocalizing with AChR clusters in NMJs (Fig. 5c1-c3). Finally, the RB4EG12 epitope showed a moderate staining that was limited to neural and synaptic BLs only (Fig. 5d1-d3).

\section{HS epitopes recognized by anti-HS antibodies abound in T. marmarota electric organ}

Because the anti-HS antibodies showed differential staining patterns with regard to nerve- and muscle-derived (extrasyn- 
Figure 3. Staining of $\mathrm{S}_{27}$ muscle cell line with anti-HS scFv antibodies. $\mathrm{S}_{27}$ cultures were grown to confluency and subsequently differentiated up to $8 \mathrm{~d}$. Cultures of different developmental stages [half confluent $(a 1-c 1), 1 \mathrm{~d}(a 2-c 2)$, and $8 \mathrm{~d}(a 3-$ c3) of differentiation] were fixed and subsequently incubated with the periplasmic fraction of $\mathrm{scFv}$ antibodies $\mathrm{AO} 4 \mathrm{~B} 05(a), \mathrm{RB} 4 \mathrm{CD} 12(b)$, and RB4EA12 (c), respectively. Bound antibodies were visualized by incubation with rabbit polyclonal anti-c-Myc IgG followed by Alexa 488conjugated goat anti-rabbit IgG. None of the epitopes recognized by any of the antibodies can be visualized at the surface of myoblasts $(a 1-c 1)$. For AO4B05, staining is not visible in aligning myoblasts (a2) or during myotube formation (a3). The epitope recognized by RB4CD12 is present in perinuclear granules in myoblasts (b1, arrows). During the alignment of myoblasts, the granular staining around the nucleus persists (b2, arrows) to change into a predominant cytosolic granular staining during myotube formation (b3). ScFv antibody RB4EA12 strongly stains perinuclear granules in myoblasts $(c 1$, arrows). In aligning myoblasts and during myotube formation, the granular staining around the nucleus persists $(c 2, c 3$, arrows). Scale bar, $25 \mu \mathrm{m}$.

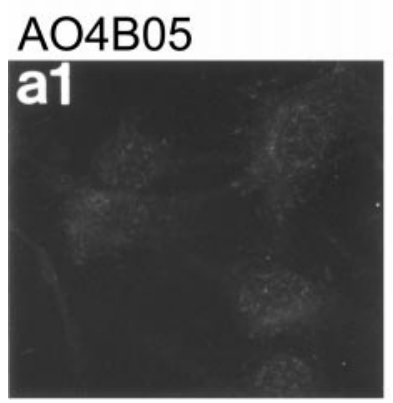

RB4CD12
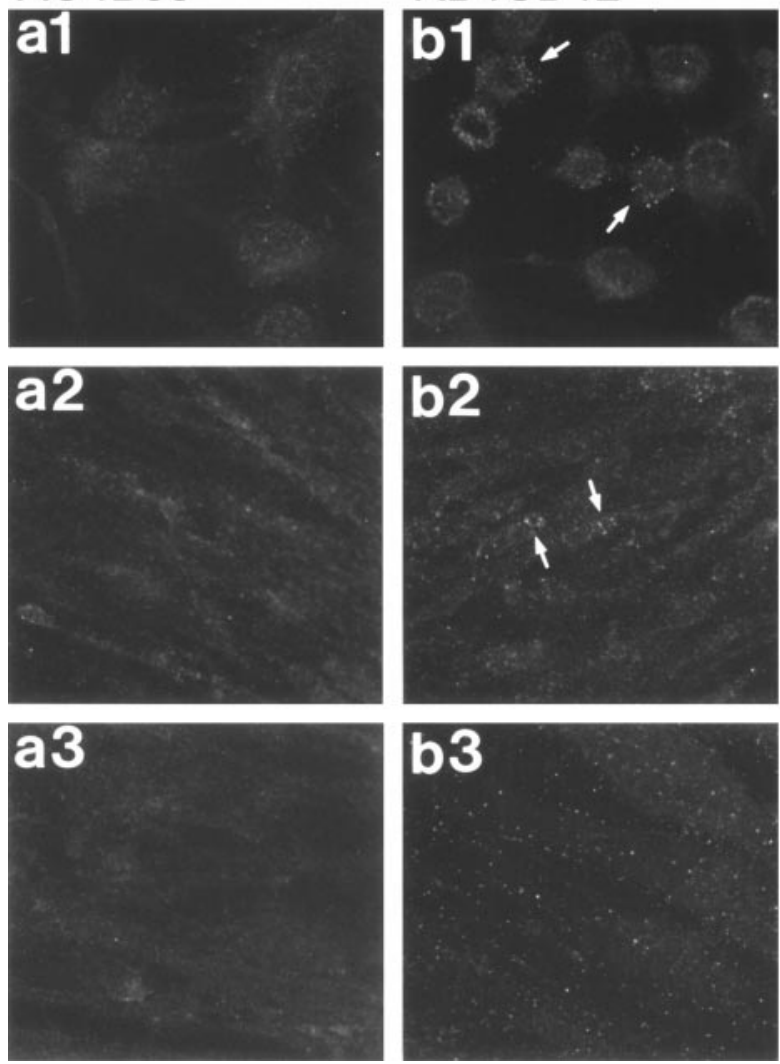
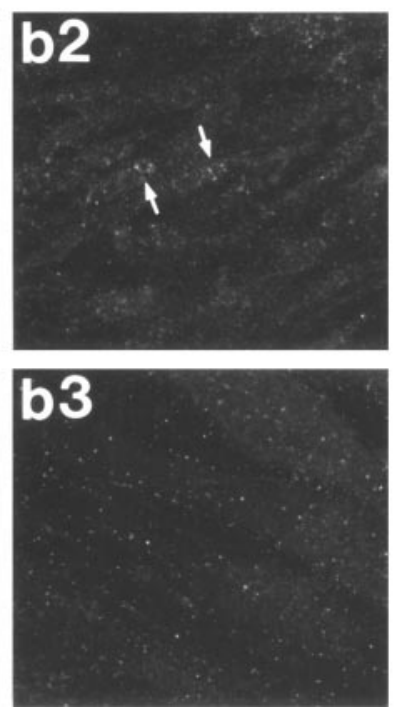
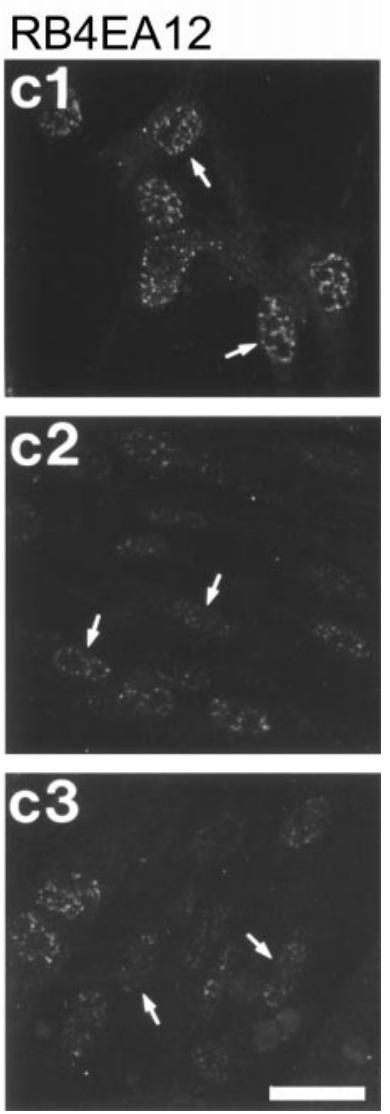

aptic and synaptic) BLs, and to investigate whether the HS epitopes are present in nonmammalian species as well, we tested the antibodies for BL staining in the electric organ of the electric ray (T. marmarota). The electric organ is evolutionary derived from muscle tissue and shows dense patches of AChR clustering on the innervated face of the electrocytes. The various anti-HS antibodies showed a distinct staining of the electric organ (Table 3, Fig. 6), ranging from a strong staining of both electrocyte and endoneural BLs [AO4B05 (Fig. 6a1$a 4$ ), AO4B08, AO4F12 (Fig. 6b1-b4), and RB4CD12], to a predominantly strong [RB4CB9 (Fig. 6c2-c4)], moderate (RB4EG12) or weak (RB4EA12) staining of the electrocyte BL. AO4B08, AO4F12 (Fig. 6b2-b4), and RB4CD12 stained specific regions of the electrocyte with a higher intensity. AO4F12 (Fig. 6b1), RB4CB9 (Fig. 6c1), and, to a lesser extent, AO4B08 and RB4CD12 stained the perineural BL. The endoneural BL was strongly stained by AO4B05 (Fig. 6a1) and to a lesser extent by AO4B08, AO4F12 (Fig. 6b1), RB4CD12, and RB4EG12.

Double-label micrographs of the epitope recognized by AO4B05 with $\alpha$-bungarotoxin showed that the AO4B05 epitope partially colocalizes with the dense patches of AChR clusters on the innervated face of the electrocytes (Fig. 6a4). Double labeling of the AO4F12 epitope showed a slightly lower staining intensity of the noninnervated membrane, as compared with the innervated membrane, except for some brightly stained regions (Fig. $6 b 4$ ). The RB4CB9 epitope was almost exclusively located at the electrocyte-innervated face, virtually completely colocalizing with the AChR clusters (Fig. 6c4).

\section{Anti-HS antibodies show a developmental occurrence of HS epitopes in skeletal muscle basal lamina}

The diversity of staining patterns obtained with the antibodies in mature skeletal muscle prompted us to investigate the occurrence of HS epitopes during muscle development. Special attention was paid to changes in the occurrence of specific HS epitopes within the endomysial, neural, and synaptic BL. This study was performed in three ways. First, cryosections of rat embryos at various developmental stages (days 10, 13, 16, and 19 in utero) were studied. In this way, the occurrence of and possible changes in BL-HS epitopes during muscular development and synaptogenesis could be studied in the presence of both muscular and neural tissue. Second, cultures of the mouse skeletal muscle cell line $\mathrm{C}_{2} \mathrm{C}_{12}$ at developmental stages ranging from half-confluent to $15 \mathrm{~d}$ of differentiation were analyzed. In doing so, we could monitor the presence of and changes in HS epitopes during myogenesis, as well as during the clustering of AChRs in the presence of muscular tissue only. Third, cryosections of denervated skeletal muscle of rat were studied. In denervated muscle cells, we looked at a possible upregulation or downregulation of HS epitopes as a result of the regeneration process.

In early embryonic stages of the rat (days 10-16), strong staining of the endomysial as well as a distinct interaction with neural BL was observed on immunostaining with AO4B05, AO4B08, AO4F12, RB4CB9, and RB4CD12. Antibody RB4EA12 predominantly stained neural tissue, whereas RB4EG12 showed an amorphous staining in developing muscle regions (data not shown). Rat embryos at day 19 in utero showed a more defined organ texture in cryosections, which enabled us to examine the presence 

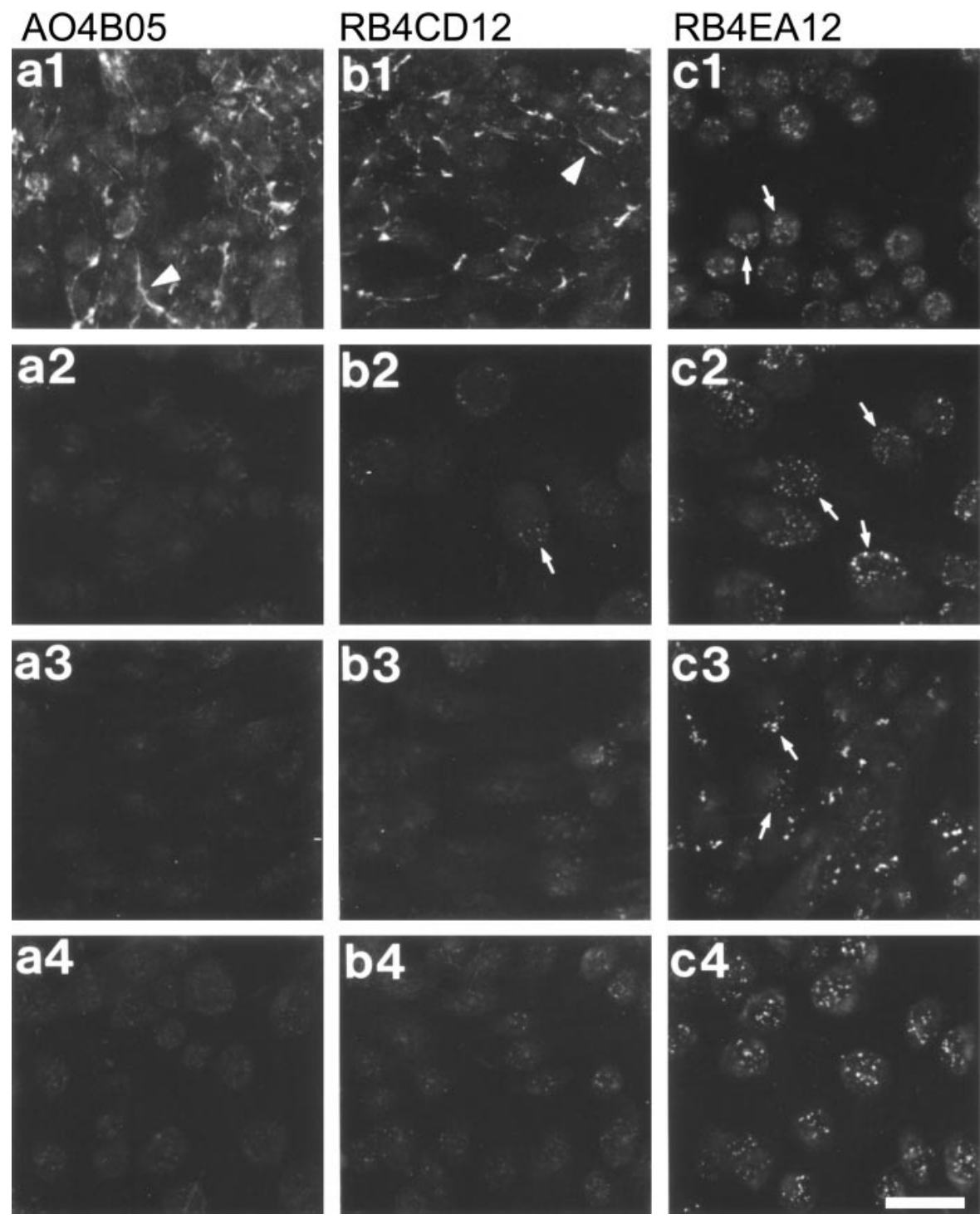
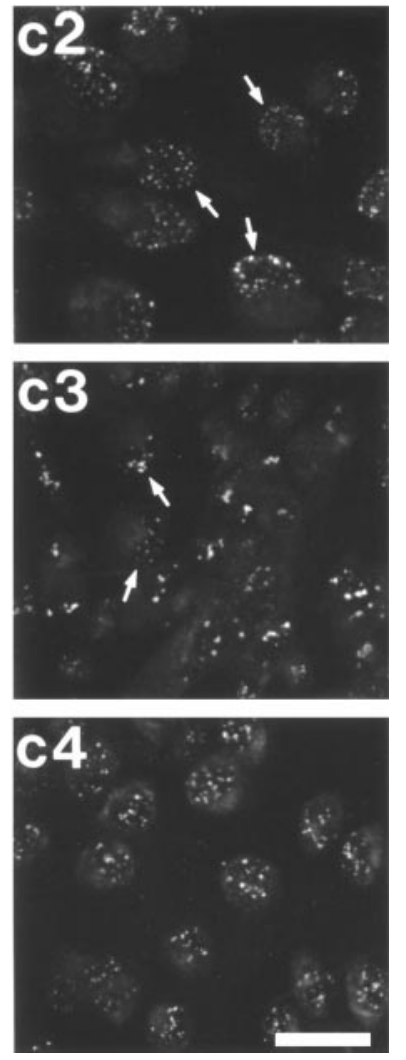

Figure 4. Staining of wild-type and glycosylationdeficient $\mathrm{CHO}$ cell lines with anti-HS scFv antibodies. CHO cultures [wild type $(a 1-c 1), N$-acetylglucosaminyl- and glucunorosyltransferase-deficient pgsD-677 (a2-c2), heparan sulfate uronic acid 2-Osulfotransferase-deficient pgsF-17 (a3-c3), and xylosyl transferase-deficient pgsA-745 (a4-c4)] were grown to confluency and subsequently fixed and incubated with the periplasmic fraction of scFv antibodies AO4B05 ( $a)$, RB4CD12 (b), and RB4EA12 (c), respectively. Bound antibodies were visualized as in Figure 3. The AO4B05 epitope is present to a high degree at the surface of wild-type $\mathrm{CHO}$ cells where cell-cell contacts are made (a1, arrowhead). Staining is not visible in any of the CHO mutant cell lines $(a 2-a 4)$. Wild-type CHO cells are moderately stained at the surface by antibody RB4CD12 at places of cell-cell contact (b1, arrowhead). In $\mathrm{CHO}$ mutant cell line pgsD-677 a faint granular perinuclear staining is visible (b2, arrow), whereas cell lines pgsF-17 and pgsA-745 show a slightly elevated background staining (b3 and $b 4$, respectively). The epitope recognized by RB4EA12 does not appear at the surface in any of the CHO cell lines but shows a distinct, perinuclear, and granular staining in all $\mathrm{CHO}$ cell lines used. In wild-type, pgsD-677, and pgsF-17 cells, these granules are predominantly located at the perinuclear region on one side of the cell (c1-c3, arrows). In pgs A-745 cells, the granular staining is present around the entire nucleus (c4). Scale bar, $25 \mu \mathrm{m}$. of the HS epitopes in greater detail (Table 3, Fig. 7). Although RB4CD12 showed a strong staining of the entire neural and endomysial BL, the staining intensity was markedly lower in the sBL (Fig. 7a). RB4CB9, on the other hand, stained the sBL considerably stronger than the extrasynaptic BL (Fig. 7b). RB4EG12, binding HS epitopes present in neural and synaptic BL in fully developed skeletal muscle, strongly interacted with HS epitopes within the sBL and showed a faint, although definite staining of the extrasynaptic BL (Fig. 7c). The epitope recognized by RB4EA12, preferentially staining neural tissue and $\mathrm{sBL}$ in mature muscle, could hardly be visualized in BL of skeletal muscle tissue at day 19 of rat embryogenesis. However, this antibody did stain large cytosolic granules (Fig. $7 d$ ). Staining of $\mathrm{BL}$ in tissues other than skeletal muscle was also observed (data not shown).

Cultures of mouse skeletal muscle cell line $\mathrm{C}_{2} \mathrm{C}_{12}$ were incubated with antibodies at stages ranging from half-confluent to $15 \mathrm{~d}$ of differentiation (Table 3, Figs. 8-10). Immunostaining with AO4B05, AO4B08, AO4F12, RB4CB9, and RB4CD12 resulted in a strong staining of the myoblast surface. An intense staining was observed at places where myoblasts made contact. However, on alignment and fusion (processes that trigger BL formation), the entire myotube surface was stained. AChR clusters, which develop on the surface of multinucleated myotubes at approximately day 3 of differentiation, were also stained by these antibodies. AO4B05 (Fig. 8), RB4CB9, and RB4CD12 (Fig. 9), especially, showed an enhanced staining of the myotube BL at sites of AChR clustering. A striking feature was that the overall staining intensity decreased strongly during differentiation for antibodies AO4B05 (Fig. 8), AO4B08, and AO4F12. Antibodies RB4EA12 and RB4EG12 were not able to stain the surface of $\mathrm{C}_{2} \mathrm{C}_{12}$ cells at any stage of differentiation. Both antibodies stained small cytosolic granules that were predominantly present near the nuclei (Fig. 10).

Incubation of cryosections of rat skeletal muscle $11 \mathrm{~d}$ after denervation with various anti-HS antibodies did not result in staining patterns that were any different from control muscle. After heparinase treatment, no differences in staining intensity with anti-HS stub antibody 3 G10 could be seen in BLs of denervated versus control muscle (data not shown).

\section{DISCUSSION}

In this paper, we report the selection of a set of unique anti-HS $\mathrm{scFv}$ antibodies. The HS epitopes recognized by these antibodies 

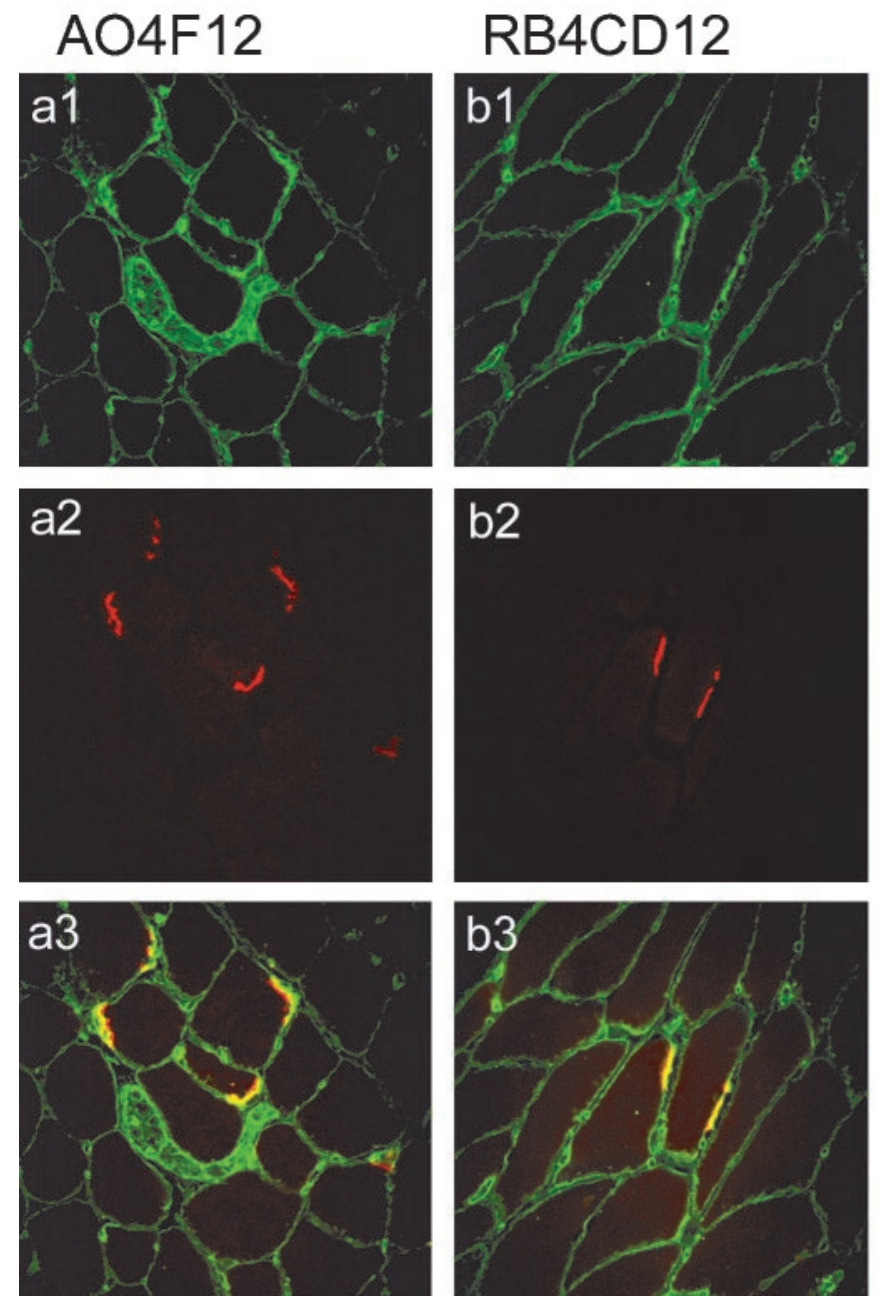
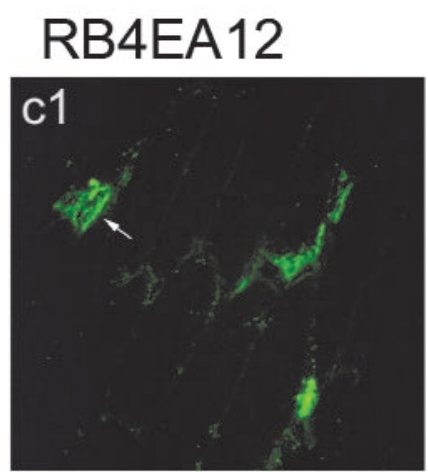

RB4EG12
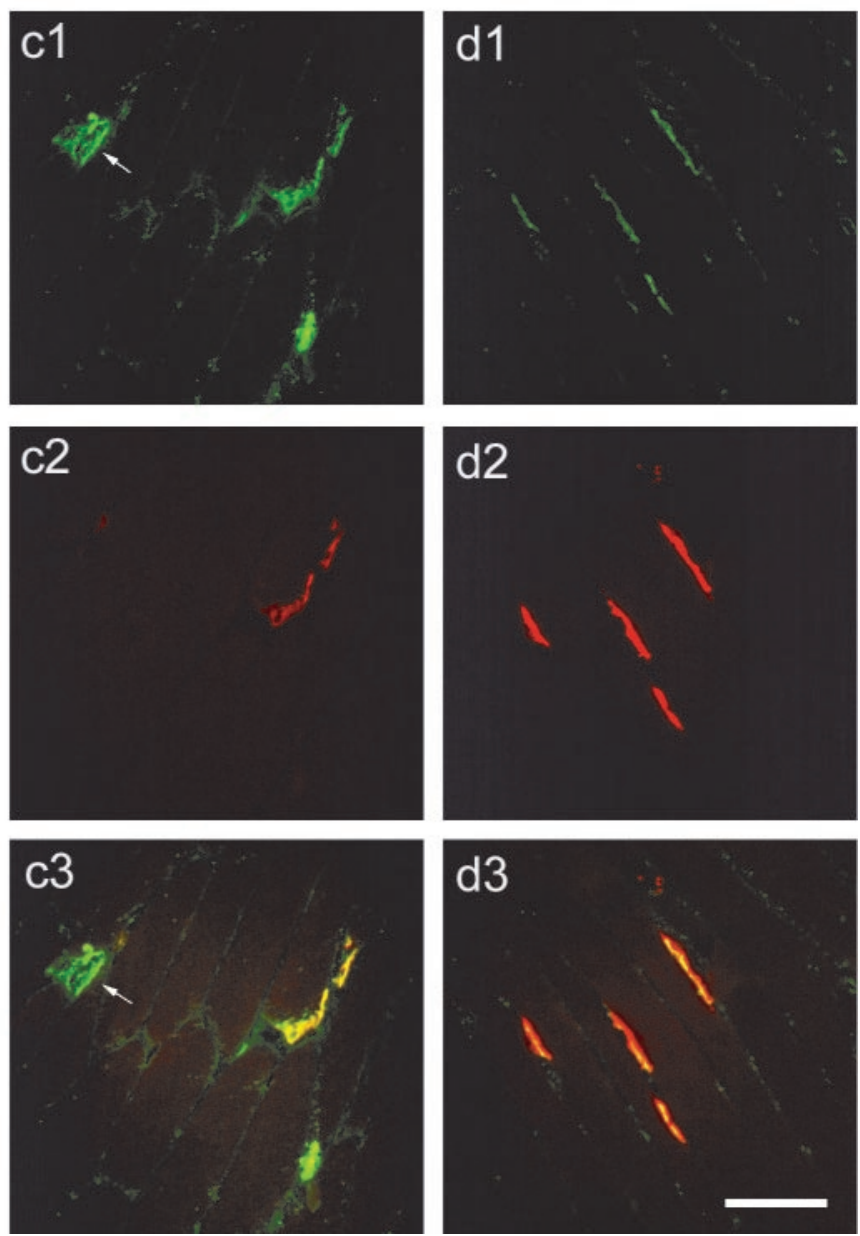

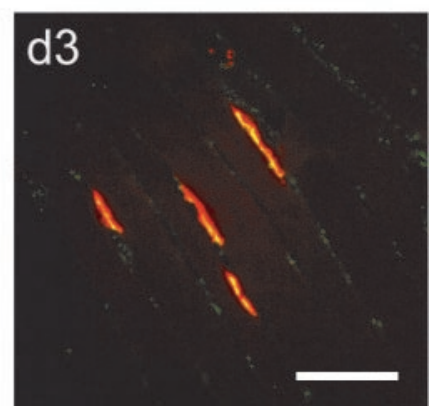

Figure 5. Staining of mouse skeletal muscle basal lamina with anti-HS scFv antibodies. Cryosections of C3H skeletal muscle were incubated with periplasmic fractions of anti-HS antibodies AO4F12 (a), RB4CD12 (b), RB4EA12 (c), and RB4EG12 (d), respectively. Bound antibodies were visualized by incubation with rabbit polyclonal anti-c-Myc IgG followed by Alexa 488-conjugated goat anti-rabbit IgG (a1-d1). AChR clusters present in the neuromuscular junction were visualized using TRITC-conjugated $\alpha$-bungarotoxin $(a 2-d 2)$. Double-label micrographs (a3- $d 3$ ) show in yellow the colocalization of the HS epitopes bound by the scFv and AChR clusters. The epitope recognized by AO4F12 is present in endoneural and perineural as well as in endomysial BLs, but is clearly more abundant in synaptic versus extrasynaptic BL (a1). Note that this epitope does not fully colocalize with AChR clusters; there is a clear overlap from the BL epitope recognition (green) via a zone in which both epitopes are present (yellow) to the dense patches of AChR (red) (a3). The RB4CD12 epitope is also present throughout neural and endomysial BLs and is slightly more abundant at NMJs (b1) but covers the entire region of AChR clustering (b3). Antibody RB4EA12 stains epitopes present in neural BL to a larger extent than those present in endomysial BL ( $c 1, c 3$, arrows), shows a high abundancy in sBL ( $c 1)$, and covers areas of AChR clustering entirely (c3). The epitope recognized by RB4EG12 hardly stains endomysial BL but resides in neural BL and at NMJs $(d 1)$, where it does not completely cover areas of AChR clustering (d3). Scale bar, $50 \mu \mathrm{m}$.

are shown to be differentially distributed in BLs of both developing and mature skeletal muscle. GAG preparations isolated from mouse and human skeletal muscle specimens were used to select a series of anti-HS antibodies by phage display. Despite the enrichment of the muscle GAG preparations for DS, only anti-HS antibodies were selected. To our knowledge, no anti-DS antibodies have been described so far.

In ELISA, all anti-HS scFv antibodies showed a differential reactivity with several HS preparations and with heparin, reflecting the epitope specificity of each antibody. The requirement of both $N$ - and $O$-sulfate groups for proper epitope recognition was shown by desulfation of heparin, which is known for its high number of disaccharide units and high levels of $N$-sulfation. Desulfation completely abolished recognition by all antibodies, and $N$-resulfation could not restore the heparin-antibody interaction. Because CS and DS are not bound by any of the antibod- ies, sulfation patterns specific for HS are likely to be important in the structure of the epitopes involved.

In our experiments, $\mathrm{CHO}$ cells showed a distinct $\mathrm{HS}$ staining for most antibodies, which was less intense than the staining of $\mathrm{C}_{2} \mathrm{C}_{12}$ cells. This is probably because $\mathrm{HS}$ from $\mathrm{CHO}$ cells is relatively poorly sulfated [ $40-45 \% N$-sulfation and $\sim 0.8$ sulfate/ disaccharide (Bame et al., 1991)]. None of the cell-surface HS epitopes recognized by any of the antibodies described here could be detected in cell lines that are defective in GAG synthesis. This was the case with the $S_{27}$ cell line, a genetic variant of the $C_{2}$ mouse skeletal muscle cell line, which is severely hampered in GAG synthesis but does align and fuse to form myotubes during differentiation (Gordon and Hall, 1989). Several CHO mutants defective in GAG synthesis caused by the loss or impaired functioning of enzymes involved in glycosylation (Esko et al., 1985; Lidholt et al., 1992) failed to show any cell surface staining, which 

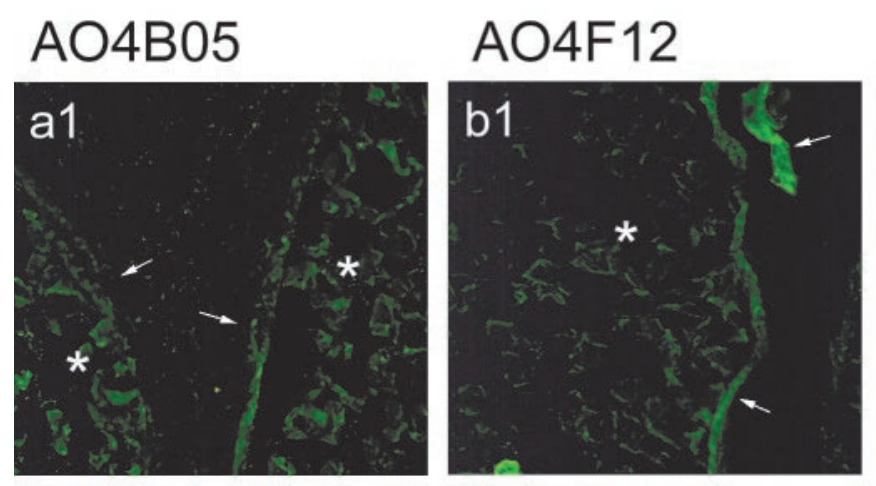

\section{RB4CB9}
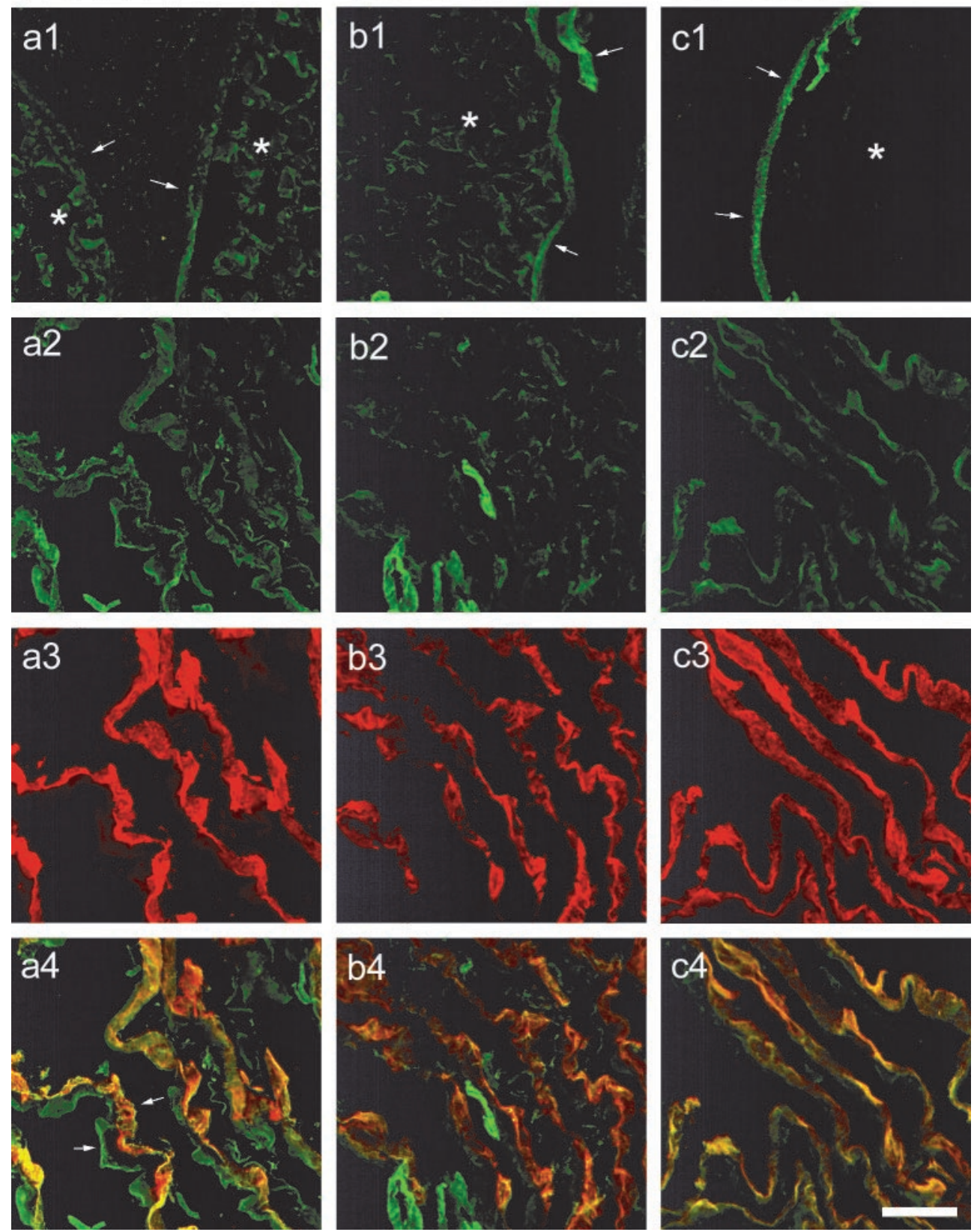

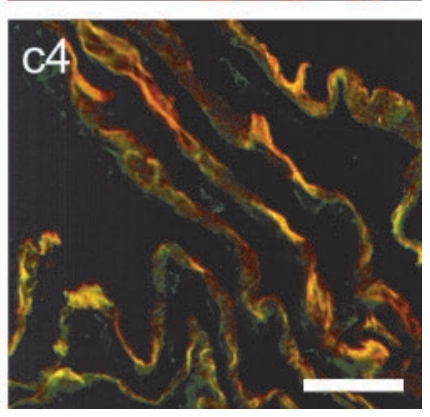

Figure 6. Staining of Torpedo electric organ with anti-HS $\mathrm{scFv}$ antibodies. Cryosections of Torpedo electric organ were incubated with periplasmic fractions of anti-HS scFv antibodies AO4B05 $(a), \operatorname{AO} 4 \mathrm{~F} 12(b)$, and $\mathrm{RB} 4 \mathrm{CB} 9(c)$, respectively. Bound antibodies $(a 1-c 1$ and $a 2-c 2)$ and AChR clusters $(a 3-c 3)$ were visualized as in Figure 5. Double-label micrographs (a4-c4) show in yellow the colocalization of AChR clusters and the HS epitopes bound by the scFvs. The AO4B05 epitope is present in large quantities in the endoneurium (a1, asterisks) and in electrocyte BLs (a2) but hardly at all in the perineurium (a1, arrows). Double staining of electrocytes reveals that this epitope is present not only on the innervated face but throughout the electrocyte BL ( $a 4$, arrows). The epitope recognized by $\mathrm{AO} 4 \mathrm{~F} 12$ is present in the endoneurium (b1, asterisk) but is more abundant in the perineural BLs (b1, arrows). In electrocytes, the presence of this epitope on the innervated face is less pronounced, whereas specific regions of the noninnervated membrane accommodate the epitope in large amounts (b2). Double staining shows this epitope to be partially colocalized with AChR clusters on the electrocyte-innervated membrane (b4). The endoneurium is not stained by antibody RB4CB9 (c1, asterisk), whereas this epitope is very abundant in the perineurium (c1, arrows). In electrocytes, its presence is restricted to the innervated membrane (c2-c4). Scale bar, $50 \mu \mathrm{m}$. indicates their inability to properly synthesize the HS epitopes involved. The granular staining seen with some antibodies in many cells may reflect the staining of certain cellular compartments such as the Golgi apparatus or lysosomes. Because of the defective cellular machinery for the correct synthesis of GAGs, immature HS epitopes or degradation products of HS molecules may be confined to these organelles.

All anti-HS scFv antibodies showed distinct reactivity in immunofluorescence with the BL of mature skeletal muscle. Staining patterns of the antibodies on human and rat muscle were consistent with those obtained on mice, reflecting an interspecies conservation of the epitopes involved. Most antibodies stained the entire muscular BL, but some antibodies showed a more intense staining in synaptic regions. Because of the presence of junctional folds in the postsynaptic membrane, BL is two- to threefold more abundant at NMJs than extrasynaptically (Sanes and Chiu, 1983). This local concentration of BL might explain the higher staining intensity of some antibodies at the NMJ, but we did not observe a higher abundance of HS in the synaptic cleft by heparitinase III digestion and anti-stub staining. A more appealing explanation is the possibility that certain HS epitopes are specifically concentrated in the sBL. The incomplete overlap of the AO4F12 epitope with AChR clusters, in contrast with e.g., RB4CD12 and RB4EA12 (Fig. 5), suggests differences in location of these epitopes within the sBL. Antibodies that predominantly recognize epitopes present in neural and synaptic BL, such as RB4EA12 and RB4EG12, may indicate the neural origin of the epitopes involved. Results obtained on aneurally cultured skeletal muscle cells support this view, because these antibodies did not stain BLs at sites of AChR clustering (see further). The synapse- 

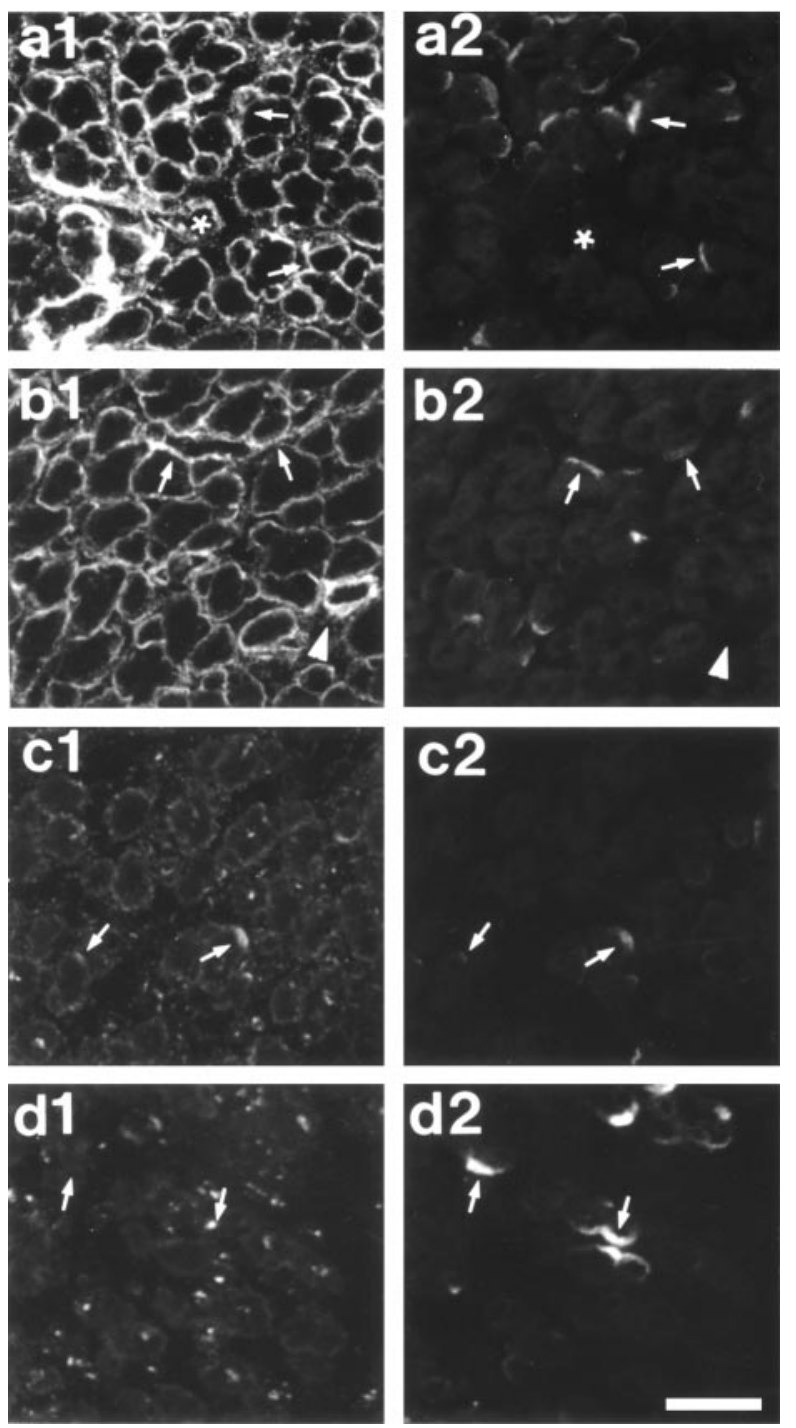

Figure 7. Staining of rat embryo skeletal muscle with anti-HS scFv antibodies. Cryosections of rat embryos (day 19 in utero) were incubated with periplasmic fractions of anti-HS scFv antibodies $\operatorname{RB} 4 \mathrm{CD} 12(a)$, RB4CB9 $(b)$, RB4EG12 $(c)$, and RB4EA12 $(d)$, respectively. Bound antibodies $(a 1-d 1)$ and AChR clusters $(a 2-d 2)$ were visualized as in Figure 5. The epitope recognized by antibody RB4CD12 is present throughout neural (asterisk) and endomysial BLs (a1) and is slightly less abundant in the sBL of developing NMJs (a1, a2, arrow). The epitope recognized by $\mathrm{RB} 4 \mathrm{CB} 9$ is present in smooth muscle BL (arrowheads point at an artery) throughout the endomysial BL (b1) but is more abundant at NMJs (b1, b2, arrows). RB4EG12 stains, at a low level, throughout the endomysial BL (granular staining in $c 1$ ), but the epitope involved is more abundant at developing NMJs ( $c 1, c 2$, arrows). The epitope recognized by RB4EA12 is only slightly present in the endomysial BL (d1) and absent in sBL (d1, d2, arrows). Scale bar, $25 \mu \mathrm{m}$.

specific occurrence of distinct HS epitopes may prove to be causal for the restricted location of NMJ-resident, HS-binding proteins such as agrin, acetylcholine esterase, growth factors, and certain laminin isoforms.

Most HS epitopes recognized by the antibodies proved to be located close to AChR clusters, present on the innervated face of electrocytes, in the electric organ of the electric ray (T. marmarota). Anti-HS antibodies recognized their epitopes, which were embedded in mutually distinct patterns and quantities within neural BLs and in BLs on both the innervated and non-

\section{AO4B05}
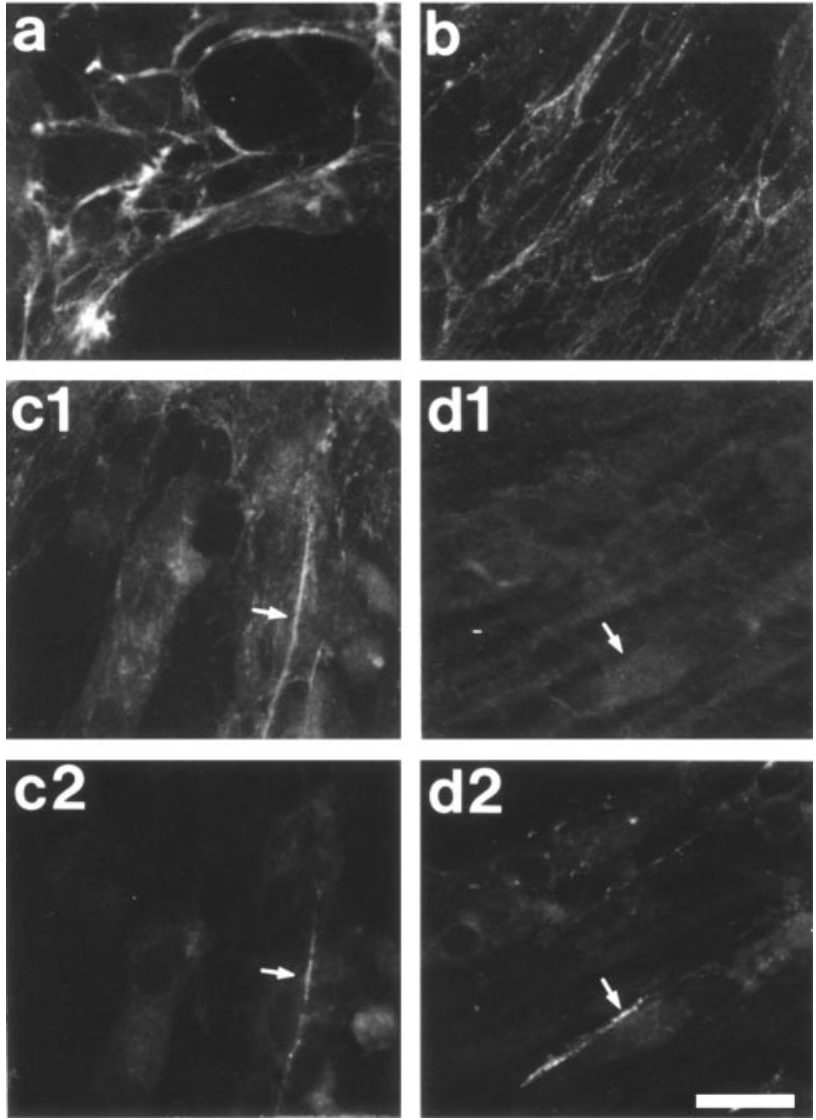

Figure 8. Staining of $\mathrm{C}_{2} \mathrm{C}_{12}$ muscle cell line with scFv antibody AO4B05 during differentiation. $\mathrm{C}_{2} \mathrm{C}_{12}$ cultures were grown to confluency and subsequently differentiated up to $15 \mathrm{~d}$. Cultures of different developmental stages [half confluent $(a), 1 \mathrm{~d}(b), 8 \mathrm{~d}(c 1, c 2)$, and $15 \mathrm{~d}(d 1, d 2)$ of differentiation] were fixed and subsequently incubated with the periplasmic fraction of $\mathrm{scFv}$ antibody AO4B05. Bound scFv antibodies $(a, b, c 1$, $d 1$ ) and AChR clusters present on the surface of multinucleated myotubes $(c 2, d 2)$ were visualized as in Figure 5 . The epitope recognized by AO4B05 is present to a high degree at the surface of myoblasts in regions where cell-cell contacts are made $(a)$. In aligning myoblasts $(b)$, a clear surface staining is visible that becomes more pronounced after myotube formation at sites where AChR clusters develop (c1, c2, arrows). As differentiation proceeds, both the staining of the BL and the staining at AChR clusters decrease (d1, d2, arrows). Scale bar, $25 \mu \mathrm{m}$.

innervated side of the electrocytes. Despite the conserved distribution of the epitopes with regard to neural, synaptic, and extrasynaptic BL among the mammals tested, the distribution within the elasmobranch electric organ appeared to differ. Extracellular matrix isolated from Torpedo electric organ can induce AChR clustering in fibroblasts (Hartman et al., 1991). The heavily glycosylated HSPG agrin appears to be involved in the clustering of AChR in Torpedo electrocytes (Cartaud et al., 1996). The staining patterns of our anti-HS antibodies on cryosections of the electric organ add proof to the mutually distinct HS epitopes involved and raise curiosity about their function in organ morphogenesis.

During myogenesis in developing rat embryos, some of the HS epitopes were present in endomysial and synaptic BL in a pattern different from that seen in mature muscular tissue. Because NMJs appear between day 14 and 16 of embryonic life (Engel, 1994), the occurrence of HS epitopes during synaptogenesis was investi- 


\section{RB4CD12}
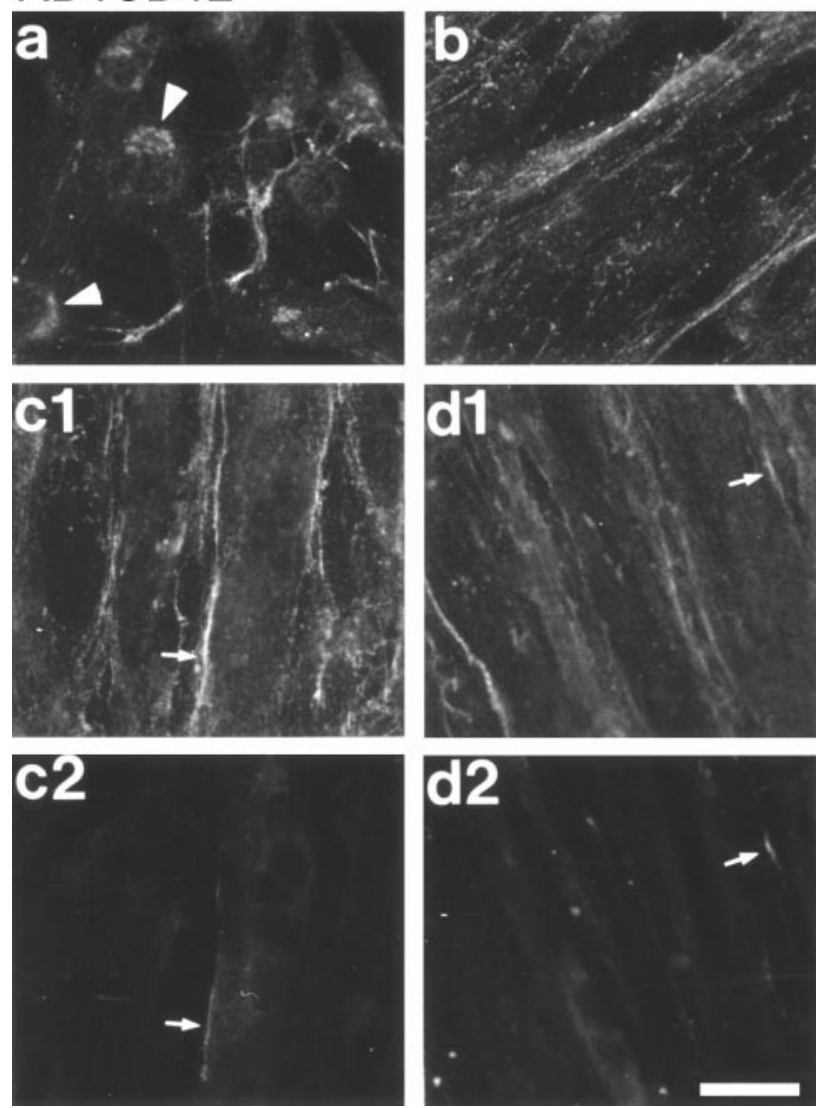

Figure 9. Staining of $\mathrm{C}_{2} \mathrm{C}_{12}$ muscle cell line with $\mathrm{scFv}$ antibody RB4CD12 during differentiation. $\mathrm{C}_{2} \mathrm{C}_{12}$ cultures were grown to confluency and subsequently differentiated up to $15 \mathrm{~d}$. Cultures of different developmental stages [half confluent $(a), 1 \mathrm{~d}(b), 8 \mathrm{~d}(c 1, c 2)$, and $15 \mathrm{~d}$ $(d 1, d 2)$ of differentiation] were fixed and subsequently incubated with the periplasmic fraction of $\mathrm{scFv}$ antibody RB4CD12. Bound $\mathrm{scFv}$ antibodies $(a, b, c 1, d 1)$ and AChR clusters present on the surface of multinucleated myotubes $(c 2, d 2)$ were visualized as in Figure 5. The RB4CD12 epitope can be visualized at the myoblast surface at sites where cells have made mutual contacts $(a)$. Note the perinuclear staining of the myoblasts at half-confluent stage (a, arrowheads). After alignment, a strong surface staining is visible $(b)$. During myotube formation, this staining intensifies, especially at sites of AChR clustering ( $c 1, c 2$, arrows). Ongoing differentiation does not lead to reduced AChR cluster staining, whereas the overall staining of the BL decreases slightly ( $d 1, d 2$, arrows). Scale bar, $25 \mu \mathrm{m}$.

gated on cryosections of embryos at days 10-19 in utero. Most antibodies stained endomysial as well as neural BLs during embryonic muscular development, as may be expected on the basis of their staining patterns in mature skeletal muscle tissue. However, clear differences in developmental appearance could be distinguished for epitopes recognized by some antibodies (RB4CB9, RB4CD12, RB4EA12, and RB4EG12), especially at sites of synaptogenesis. Local binding of growth factors and cytokines to specific HS sequences, as reviewed recently by Lyon and Gallagher (1998), may prove to be elemental in tissue morphogenesis. The distinct distribution in both time and space of these HS epitopes argues for such a regulatory mechanism.

The HS epitopes recognized by our antibodies were present in $\mathrm{C}_{2} \mathrm{C}_{12}$ skeletal muscle cells at various stages of differentiation. Aneurally grown $\mathrm{C}_{2} \mathrm{C}_{12}$ myoblasts start aligning when they reach confluency. When culture medium is changed to differentiation medium containing $10 \%$ rat brain extract, $\mathrm{AChR}$ clusters appear

\section{RB4EA12}
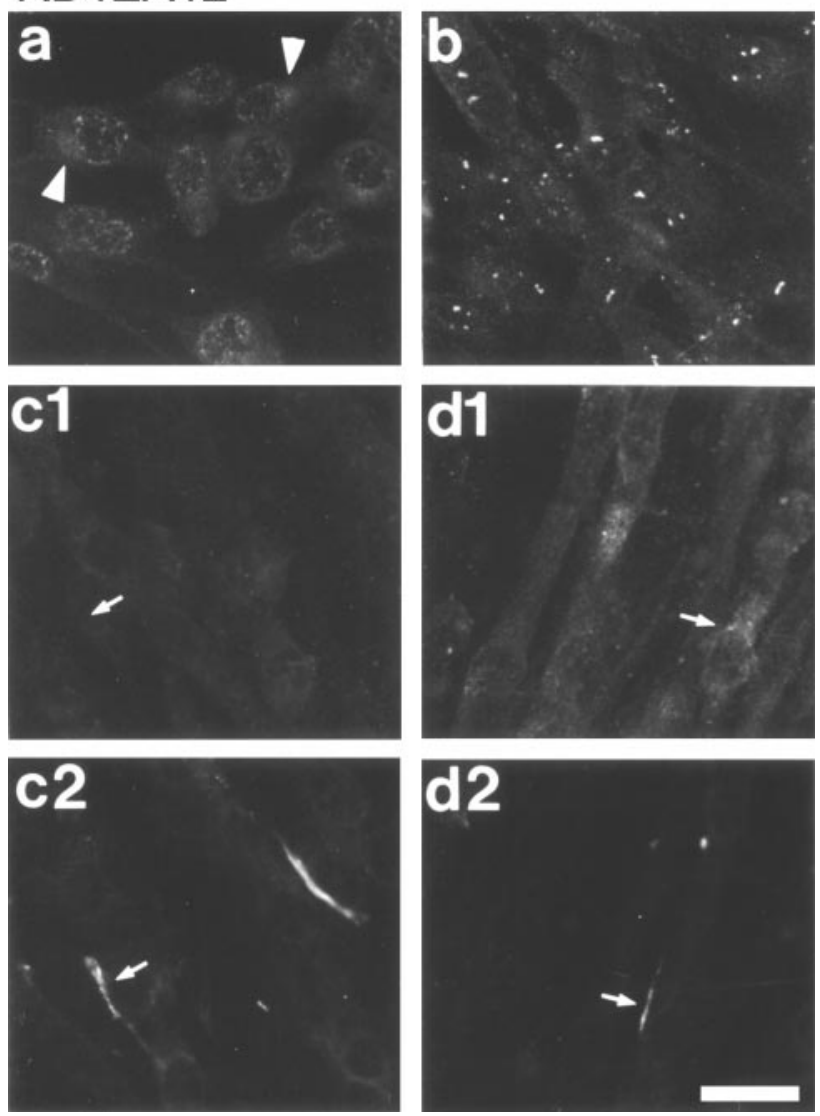

Figure 10. Staining of $\mathrm{C}_{2} \mathrm{C}_{12}$ muscle cell line with $\mathrm{scFv}$ antibody RB4EA12 during differentiation. $\mathrm{C}_{2} \mathrm{C}_{12}$ cultures were grown to confluency and subsequently differentiated up to $15 \mathrm{~d}$. Cultures of different developmental stages [half confluent $(a), 1 \mathrm{~d}(b), 8 \mathrm{~d}(c 1, c 2)$, and $15 \mathrm{~d}$ $(d 1, d 2)$ of differentiation] were fixed and subsequently incubated with the periplasmic fraction of $\mathrm{scFv}$ antibody RB4EA12. Bound $\mathrm{scFv}$ antibodies $(a, b, c 1, d 1)$ and AChR clusters present on the surface of multinucleated myotubes $(c 2, d 2)$ were visualized as in Figure 5. The epitope recognized by RB4EA12 is not present at the surface of myoblasts in regions where cell-cell contacts have been made $(a)$. Note the faint staining in the perinuclear region of myoblasts at the half-confluent stage (a, arrowheads). A granular staining within the cytosol is visible in early stages of alignment $(b)$ but disappears during myotube formation $(c 1)$. During further differentiation, no BL staining is seen at AChR clusters $(d 1, d 2$, arrows). Nevertheless, a faint perinuclear staining occurs in some myotubes displaying AChR clusters (d1, d2, arrows). Scale bar, $25 \mu \mathrm{m}$.

at approximately day 3 of differentiation (Portiér et al., 1999). On mutual contact, $\mathrm{C}_{2} \mathrm{C}_{12}$ myoblasts expressed most of the $\mathrm{HS}$ epitopes described in this paper in large quantities on their surface. Alignment and fusion resulted in a complete staining of the newly formed BL by corresponding antibodies. These observations are in accordance with the threefold increase in HS synthesis in myotube cultures, compared with proliferating or aligning cultures (Noonan et al., 1986). Some antibodies showed steady levels or even a marked increase in overall staining intensity of the BL during further differentiation, consistent with the upregulation of the HSPG glypican during $\mathrm{C}_{2} \mathrm{C}_{12}$ differentiation (Brandan et al., 1996). Overall BL staining intensity of other antibodies decreased during later stages of differentiation. These results may be related to observations of Larraín et al. (1997a,b) on downregulation of the HSPGs perlecan and syndecan-1 during $\mathrm{C}_{2} \mathrm{C}_{12}$ cell differentiation. AChR cluster formation was accompa- 
nied by a strong local increase of certain HS epitopes, arguing for a possible role of these epitopes in the clustering of this ion channel. Antibodies RB4EA12 and RB4EG12 were not capable of $\mathrm{BL}$ staining at any stage of $\mathrm{C}_{2} \mathrm{C}_{12}$ cell differentiation, in accordance with their supposed neural origin.

Attempts to detect possible changes in the abundance of HS epitopes in denervated skeletal muscle proved to be elusive. Endomysial and neural BLs persist after damage or degeneration of either muscle or nerve cells, or both (Hall and Sanes, 1993). Synaptic and extrasynaptic proteoglycan deposits are conserved in both size and morphology in denervated skeletal muscle (Anderson et al., 1984), serving as scaffolds for the regeneration of both muscle and nerve tissue, thus causing NMJs to develop at sites where they were present before the degeneration. Moreover, Fadic and coworkers (1990) reported proteoglycan synthesis to be upregulated after denervation. Recently, GAGs were shown to be potent stimulants of insulin-like growth factor-1-mediated muscle reinnervation (Gorio et al., 1998). Because HS binds several growth factors involved in tissue morphogenesis and because of the unique distribution of certain HS epitopes, we suspect certain roles for HS epitopes in this regeneration process.

In conclusion, we show that it is possible to select for highly specific anti-HS antibodies against GAG preparations from skeletal muscle. The antibody-defined HS epitopes have distinct distribution characteristics in skeletal muscle BL and are similarly distributed in humans, rats, and mice. Obvious differences in extrasynaptic and synaptic BL staining were observed in mature versus developing skeletal muscle. The unique distribution patterns in skeletal muscle of the HS epitopes recognized by the scFv antibodies described in this article, both in time and in space, raise questions as to the biological roles of these HS epitopes. Of special interest are their roles in myogenesis, more specifically in synaptogenesis and the accompanying postsynaptic specializations such as the clustering of AChRs and other ion channels. The occurrence of these HS epitopes in HSPGs that have already been implicated in developmental processes awaits further investigation. Tools are now available to study more accurately the role of HS epitopes separate from their core protein.

\section{REFERENCES}

Anderson JM, Fambrough DM (1983) Aggregates of acetylcholine receptors are associated with plaques of a basal lamina heparan sulfate proteoglycan on the surface of skeletal muscle cells. J Cell Biol 97:1396-1411.

Anderson MJ, Klier FG, Tanguay KE (1984) Acetylcholine receptor aggregation parallels the deposition of a basal lamina proteoglycan during development of the neuromuscular junction. J Cell Biol 99:1769-1784.

Bame KJ, Lidholt K, Lindahl U, Esko JD (1991) Biosynthesis of heparan sulfate: coordination of polymer-modification reactions in a Chinese hamster ovary cell mutant defective in $N$-sulfotransferase. J Biol Chem 266:10287-10293.

Bayne EK, Anderson MJ, Fambrough DM (1984) Extracellular matrix organization in developing muscle: correlation with acetylcholine receptor aggregates. J Cell Biol 99:1486-1501.

Brandan E, Maldonado M, Garrido J, Inestrosa NC (1985) Anchorage of collagen-tailed acetylcholinesterase to the extracellular matrix is mediated by heparan sulfate proteoglycans. J Cell Biol 101:985-992.

Brandan E, Carey DJ, Larraín J, Melo F, Campos A (1996) Synthesis and processing of glypican during differentiation of skeletal muscle cells. Eur J Cell Biol 71:170-176.

Campanelli JT, Roberds SL, Campbell KP, Scheller RH (1994) A role for dystrophin-associated glycoproteins and utrophin in agrin-induced AChR clustering. Cell 77:663-674.

Cartaud A, Ludosky MA, Haasemann M, Jung D, Campbell K, Cartaud J (1996) Non-neural agrin codistributes with acetylcholine receptors during early differentiation of Torpedo electrocytes. J Cell Sci 109:1837-1846.

Chen X, Raab G, Deutsch U, Zhang J, Ezzell RM, Klagsbrun M (1995) Induction of heparin-binding EGF-like growth factor expression during myogenesis. J Biol Chem 270:18285-18294.

Chiu AY, Ko J (1994) A novel epitope of entactin is present at the mammalian neuromuscular junction. J Neurosci 14:2809-2817.

Crisona NJ, Allen KD, Strohman RC (1998) Muscle satellite cells from dystrophic $(m d x)$ mice have elevated levels of heparan sulfate proteoglycan receptors for fibroblast growth factor. J Muscle Res Cell Motil 19:43-51.

David G, Mei Bai X, Van Der Schueren B, Cassiman J-J, Van Den Berghe H (1992) Developmental changes in heparan sulfate expression: in situ detection with mAbs. J Cell Biol 119:961-975.

Degens H, Turek Z, Hoofd LJC, van 't Hof MA, Brinkhorst RA (1992) The relationship between capillarisation and fibre types during compensatory hypertrophy of the plantaris muscle in the rat. $\mathrm{J}$ Anat 180:455-463.

Dmytrenko GM, Scher MG, Poiana G, Baetscher M, Bloch RJ (1990) Extracellular glycoproteins at acetylcholine receptor clusters of rat myotubes are organized into domains. Exp Cell Res 189:41-50.

Engel AG (1994) The neuromuscular junction. In: Myology (Engel AG, Banker BQ, eds), pp 261-302. New York: McGraw-Hill.

Esko JD, Steward TE, Taylor WT (1985) Animal cell mutants defective in glycosaminoglycan biosynthesis. Proc Natl Acad Sci USA 82:3197-3201.

Fadic R, Brandan E, Inestrosa NC (1990) Motor nerve regulates muscle extracellular matrix proteoglycan expression. J Neurosci 10:3516-3523.

Ferns MJ, Campbell JT, Hoch W, Scheller RH, Hall Z (1993) The ability of agrin to cluster AChRs depends on alternative splicing and on cell surface proteoglycans. Neuron 11:491-502.

Fischbach GD, Rosen KM (1997) A neuromuscular junction neuregulin. Annu Rev Neurosci 20:429-458.

Gordon H, Hall ZW (1989) Glycosaminoglycan variants in the C2 muscle cell line. Dev Biol 135:1-11.

Gordon H, Lupa M, Bowen D, Hall Z (1993) A muscle cell variant defective in glycosaminoglycan biosynthesis forms nerve-induced but not spontaneous clusters of the acetylcholine receptor and the $43 \mathrm{kDa}$ protein. J Neurosci 13:586-595.

Gorio A, Vergani L, De Tollis A, Di Giulio AM, Torsello A, Cattaneo L, Muller EE (1998) Muscle reinnervation following neonatal nerve crush. Interactive effects of glycosaminoglycans and insulin-like growth factor-1. Neuroscience 82:1029-1037.

Halfter W, Dong S, Schurer B, Cole GJ (1998) Collagen XVIII is a basement membrane heparan sulfate proteoglycan. J Biol Chem 273:25404-25412.

Hall ZW, Sanes JR (1993) Synaptic structure and development: the neuromuscular junction. Cell 72:99-121.

Hartman DS, Millar NS, Claudio T (1991) Extracellular synaptic factors induce clustering of acetylcholine receptors stably expressed in fibroblasts. J Cell Biol 115:165-177.

Hirano Y, Kidokoro Y (1989) Heparin and heparan sulfate partially inhibit induction of acetylcholine receptor accumulation by nerve in Xenopus culture. J Neurosci 9:1555-1561.

Iglesias M, Ribera J, Esquerda JE (1992) Treatment with digestive agents reveals several glycoconjugates specifically associated with rat neuromuscular junction. Histochemistry 97:125-131.

Larraín J, Alvarez J, Hassell JR, Brandan E (1997a) Expression of perlecan, a proteoglycan that binds myogenic inhibitory basic fibroblast growth factor, is down regulated during skeletal muscle differentiation. Exp Cell Res 234:405-412.

Larraín J, Cizmeci-Smith G, Troncoso V, Stahl RC, Cary DJ, Brandan E (1997b) Syndecan-1 expression is down-regulated during myoblast terminal differentiation. J Biol Chem 272:18418-18424.

Lidholt K, Weinke JL, Kiser CS, Lugemwa FN, Bame KJ, Cheifetz S, Massagué J, Lindahl U, Esko JD (1992) A single mutation affects both $\mathrm{N}$-acetylglucosaminyltransferase and glucuronosyltransferase activities in a Chinese hamster ovary cell mutant defective in heparan sulfate biosynthesis. Proc Natl Acad Sci USA 89:2267-2271.

Lyon M, Gallagher JT (1998) Bio-specific sequences and domains in heparan sulfate and the regulation of cell growth and adhesion. Matrix Biol 17:485-493.

Martin PT, Scott LJC, Porter BE, Sanes JR (1999) Distinct structures and functions of related pre- and postsynaptic carbohydrates at the mammalian neuromuscular junction. Mol Cell Neurosci 13:105-118. 
Mook-Jung I, Gordon H (1996) Acetylcholine receptor clustering associates with proteoglycan biosynthesis in $\mathrm{C} 2$ variant and heterokaryon muscle cells. J Neurobiol 31:210-218.

Nissim A, Hoogenboom HR, Tomlinson IM, Flynn G, Midgley C, Lane D, Winter G (1994) Antibody fragments from a "single pot" phage display library as immunochemical reagents. EMBO J 13:692-698.

Noonan DM, Malemud CJ, Przybylski RJ (1986) Biosynthesis of heparan sulfate proteoglycans of developing chick breast skeletal muscle in vitro. Exp Cell Res 166:327-339.

Noonan DM, Fulle A, Valente P, Cai S, Horigan E, Sasaki M, Yamada Y, Hassel JR (1991) The complete sequence of perlecan, a basement membrane heparan sulfate proteoglycan, reveals extensive similarity with laminin A chain, low density lipoprotein-receptor, and the neural cell adhesion molecule. J Biol Chem 266:22939-22947.

Olwin BB, Rapraeger A (1992) Repression of myogenic differentiation by aFGF, bFGF, and K-FGF is dependent on cellular heparan sulfate. J Cell Biol 118:631-639.

Olwin BB, Arthur K, Hannon K, Hein P, McFall A, Riley B, Szebenyl G, Zhou Z, Zuber ME, Rapraeger AC, Fallon JF, Kudla AJ (1994) Role of FGFs in skeletal muscle and limb development. Mol Reprod Dev 39:90-101.

Patton BL, Miner JH, Chiu AY, Sanes JR (1997) Distribution and function of laminins in the neuromuscular system of developing, adult, and mutant mice. J Cell Biol 139:1507-1521.

Peng HB, Baker LP, Chen Q (1991) Induction of synaptic development in cultured muscle cells by basic fibroblast growth factor. Neuron 6:237-246.

Peng HB, Ali AA, Dai Z, Daggett DF, Raulo E, Rauvala H (1995) The role of heparin-binding growth-associated molecule (HB-GAM) in the postsynaptic induction in cultured muscle cells. J Neurosci 15:3027-3038.

Peng HB, Ali AA, Daggett DF, Rauvala H, Hassell JR, Smalheiser NR (1998) The relationship between perlecan and dystroglycan and its implication in the formation of the neuromuscular junction. Cell Adhes Commun 5:475-489.

Portiér GL, Benders AAGM, Oosterhof A, Veerkamp JH, van Kuppevelt TH (1999) Differentiation markers of mouse $\mathrm{C}_{2} \mathrm{C}_{12}$ and rat $\mathrm{L}_{6}$ myogenic cell lines and the effect of differentiation medium. In Vitro Cell Dev Biol Anim 35:219-227.

Rapraeger AC, Krufka A, Olwin BB (1991) Requirement of heparan sulfate for bFGF-mediated fibroblast growth and myoblast differentiation. Science 252:1705-1708.

Ruegg MA, Bixby JL (1998) Agrin orchestrates synaptic differentiation at the vertebrate neuromuscular junction. Trends Neurosci 21:22-27.
San Antonio JD, Slover J, Lawler J, Karnovski MJ, Lander AD (1993) Specificity in the interactions of extracellular matrix proteins with subpopulations of the glycosaminoglycan heparin. Biochemistry 32:4746-4755.

Sanes JR (1982) Laminin, fibronectin, and collagen in synaptic and extrasynaptic portions of muscle fiber basement membrane. J Cell Biol 93:442-451.

Sanes JR (1986) The extracellular matrix. In: Myology (Engel AG, Banker BQ, eds), pp 155-175. New York: McGraw-Hill.

Sanes JR, Cheney JM (1982) Lectin binding reveals a synapse-specific carbohydrate in skeletal muscle. Nature 300:646-647.

Sanes JR, Chiu AY (1983) The basal lamina of the neuromuscular junction. Cold Spring Harb Symp Quant Biol 48:667-678.

Sanes JR, Engvall E, Butkowski R, Hunter DD (1990) Molecular heterogeneity of basal laminae: isoforms of laminin and collagen IV at the neuromuscular junction and elsewhere. J Cell Biol 111:1685-1699.

Szabat E, Rauvala H (1996) Role of HB-GAM (heparin-binding growth associated molecule) in proliferation arrest in cells of the developing rat limb and its expression in differentiating neuromuscular system. Dev Biol 178:77-89.

Tomlinson IM, Walter G, Marks JD, Llewelyn MB, Winter G (1992) The repertoire of human germline $V_{H}$ sequences reveals about fifty groups of $\mathrm{V}_{\mathrm{H}}$ segments with different hypervariable loops. J Mol Biol 227:776-798.

Tsen G, Halfter W, Kröger S, Cole GJ (1995) Agrin is a heparan sulfate proteoglycan. J Biol Chem 270:3392-3399.

van den Born J, van den Heuvel LPWJ, Bakker MAH, Veerkamp JH, Assmann KJM, Berden JHM (1992) Production and characterization of a monoclonal antibody against human glomerular basement membrane. Kidney Int 41:115-123.

van Kuppevelt TH, Dennissen MABA, Van Venrooij WJ, Hoet RMA, Veerkamp JH (1998) Generation and application of type-specific antiheparan sulfate antibodies using phage display technology. J Biol Chem 273:12960-12966.

Wallace BG (1990) Inhibition of agrin-induced acetylcholine-receptor aggregation by heparin, heparan sulfate, and other polyanions. J Neurosci 10:3576-3582.

Wright TN, Heinengard DK, Hascall VC (1991) Proteoglycansstructure and function. In: Cell biology of extracellular matrix (Hay ED, ed), pp 45-78. New York: Plenum.

Zhou H, Muramatsu T, Halfter W, Tsim KWK, Peng HB (1997) A role of midkine in the development of the neuromuscular junction. Mol Cell Neurosci 10:56-70. 